\title{
Responsabilidad, autoridad y democracia una exploración crítica de la filosofía del derecho penal de Antony Duff
}

\author{
Responsibility, authority and democracy \\ A critical exploration of Antony Duff's \\ Philosophy of criminal law
}

Juan Pablo Mañalich R.*

Recepción y evaluación de propuesta: 01/12/2016.

Aceptación: 01/02/2017.

Recepción y aceptación final: 01/03/2017.

Resumen: El trabajo explora algunos aspectos centrales del programa de una filosofía del derecho penal desarrollado por Antony Duff, en referencia a tres ejes fundamentales de su pensamiento, internamente conectados: su concepción relacional de la responsabilidad, su caracterización de la autoridad del derecho y su comprensión de la democracia como fuente de legitimación. Sobre esta base, se persigue mostrar la inestabilidad de su recurso a la distinción entre mala in se y mala prohibita, así como la falta de plausibilidad de su concepción no-procedimentalista de la producción democrática del derecho.

Palabras clave: responsabilidad, autoridad y razones para la acción, democracia y legislación, mala in se y mala prohibita

* Universidad de Chile, correo electrónico: jpmanalich@derecho.uchile.cl Agradezco a los participantes del seminario de investigadores de la Facultad de Derecho de la Universidad de Chile, por las observaciones y objeciones formuladas en la discusión de un borrador preliminar del presente trabajo, y especialmente a Sebastián Figueroa Rubio, por las múltiples y muy fértiles sugerencias que generosamente me hiciera llegar para mejorar el texto. 
Juan Pablo Mañalich R.

\begin{abstract}
The paper explores some central aspects of Antony Duff's program of a philosophy of criminal law, in reference to three fundamental axes, internally connected: his relational conception of responsibility, his characterization of law's authority, and his understanding of democracy as legitimation source. Upon this basis, the paper seeks to show the instability of Duff's appeal to the distinction between mala in se and mala prohibita, as well as the lack of plausibility of his non-proceduralistic conception of the democratic production of law. Keywords: responsibility, authority and reasons for action, democracy and legislation, mala in se and mala prohibita
\end{abstract}

One question we must then ask ourselves is this: how confident are we that all those who appear as defendants in our courts are properly answerable to us for their crimes? (Duff, Answering for Crime, pág. 191)

\title{
I. Introducción
}

La reciente publicación de Sobre el castigo (México y Buenos Aires: Siglo XXI, 2015), del filósofo del derecho escocés Antony Duff, es una muy buena noticia para los lectores de habla hispana interesados en la reflexión filosófica acerca del derecho penal. Pues Duff es, sin duda alguna, una de las figuras principales del decurso que ha dado lugar, en un arco de tiempo que gruesamente comprende las últimas cuatro décadas, a la emergencia de un muy fecundo género de indagación teórica, filosóficamente orientada, en las bases, la estructura y el funcionamiento de los sistemas de derecho penal enmarcados en la tradición del common law, cultivado por muy prominentes filósofos y juristas de habla inglesa ${ }^{1}$. En este concierto, la singularidad de la

1 Lo cual se ve reflejado en una ya copiosa serie de volúmenes colectivos, varios de los cuales han sido coordinados por Duff; véase por ejemplo Duff. A., Philosophy and the Criminal Law. Principle and Critique. Cambridge: Cambridge University Press, 1998, así como Duff, A. y Green, S., 
Responsabilidad, autoridad y democracia una exploración crítica ...

obra de Duff se halla en su muy consistente esfuerzo por articular una concepción suficientemente omnicomprensiva de los regímenes de derecho penal adscritos a esa tradición, a partir de premisas obtenidas, en lo fundamental, de la filosofía analítica del lenguaje y de la acción, por un lado, y de la filosofía política, por otro ${ }^{2}$. Sobre esta base, el rasgo absolutamente diferenciador de esa misma concepción consiste en su pretensión autoconscientemente idealizadora, que Duff identifica con la vocación distintivamente normativa (en oposición a descriptiva) de su enfoque ${ }^{3}$. En esta pretensión idealizadora tendría que sustentarse, al mismo tiempo, el propio potencial crítico de tal concepción, desde el punto de vista de su adecuación como herramienta de impugnación de los regímenes de derecho penal positivo "efectivamente existentes", en función de su mayor o menor falta de satisfacción de los presupuestos de legitimidad delineados a través de la correspondiente imagen idealizada.

A partir de este reconocimiento, y en atención a que una valoración pormenorizada de los trabajos reunidos en Sobre el castigo ha podido ver recientemente la luz ${ }^{4}$, en lo que se sigue se intentará reconstruir algunos debates fundamentales de la filosofía jurídico-penal contemporánea en los cuales inciden algunos planteamientos centrales de la obra de Duff, la mayor parte de los cuales encuentra su formulación más desarrollada en su muy importante monografía Answering for Crime, de 2007.

Philosophical Foundations of Criminal Law. Oxford: Oxford University Press, 2011.

2 Un reconocimiento especialmente elocuente de la importancia de su obra está constituido por el volumen colectivo dedicado a la revisión de los principales aspectos de su filosofía jurídico-penal; véase Cruft, R., Kramer, M. y Reiff, M., Crime, Punishment and Responsibility. The Jurisprudence of Antony Duff. Oxford: Oxford University Press, 2011.

3 Véase especialmente Duff. A., Answering for Crime, Oxford y Portland: Hart Publishing, , 2007. pág. 6 ss.

4 Véase Mañalich, J. P. Duff, A., Sobre el castigo, México: Siglo XXI, 2015, Derecho y Crítica Social 2(2): 265-274, 2016. 
Juan Pablo Mañalich R.

\section{La responsabilidad como presupuesto de la punibilidad}

\section{II.1. Decisiones de criminalización y condiciones de punibilidad}

En una serie de publicaciones individuales y colectivas, Duff se ha ocupado detalladamente de la manera en que la específica fisonomía del proceso penal propio de una sociedad organizada democráticamente puede hacer más probable una forma de comunicación que involucre, triangularmente, al imputado, a la (eventual) víctima y a la comunidad a la que aquél y esta pertenecen, en términos tales que, de conducir el desarrollo del proceso a un veredicto de culpabilidad, la decisión de condena pronunciada sobre el acusado pueda ser interpretada como expresiva de la censura comunitaria de la injusticia perpetrada por el hechor, así como de la solidaridad comunitaria para con la víctima por su padecimiento de esa misma injusticia ${ }^{5}$. Esto último es lo que Duff tematiza en el sentido de que semejante articulación comunicativa del procesamiento del "agravio" (wrong) inmediatamente padecido por la víctima haría posible que aquél devenga un "agravio compartido" (shared wrong), en el sentido de tratarse de una injusticia que, por vía de identificación con la víctima, la comunidad hace suya ${ }^{6}$. Ello sería indicativo de que aquellas formas de comportamiento que el derecho penal paradigmáticamente criminaliza exhiben el estatus de un "agravio público" (public wrong).

Desde luego, Duff hace explícito que hay delitos cuya específica incorrección (wrongness) está efectivamente determinada por un

5 Véase especialmente Duff, A., Trials and Punishments, Cambridge: Cambridge University Press, 1986, págs. 99 ss., 23 ss.; Duff, A.; Farmer, L.; Marshall, S. y Tadros, V., The Trial on Trial, vol. 1: Truth and Due Process, Oxford: Hart Publishing, 2004. pág. 1 ss.; Duff, A.; Farmer, L.; Marshall, S. y Tadros, V., The Trial on Trial, vol. 2: Judgment and Calling to Account, Oxford: Hart Publishing, 2006, pág. 1 ss.; y Duff, A.; Farmer, L.; Marshall, S. y Tadros, V, The Trial on Trial, vol. 3: Towards an Normative Theory of the Criminal Trial, Oxford: Hart Publishing, 2007, págs. 93 ss., 199 ss.

6 Duff , A., Answering... op. cit., pág. 140 ss. 
Responsabilidad, autoridad y democracia una exploración crítica ...

agravio padecido por el "público" o la comunidad como tal". Su punto es, más bien, que semejante caracterización no es pertinente tratándose de muchos de los delitos que, siendo constitutivos de mala in se, indudablemente integran el núcleo del ordenamiento jurídico-penal de la generalidad de las actuales sociedades occidentales -incluidos el homicidio, la agresión o lesión corporal y la violación, entre otros-, cuya específica incorrección no puede verse sino distorsionada si se la especifica de un modo que no dé cuenta, en primerísimo lugar, del agravio directamente sufrido por su víctima. Duff ejemplifica el punto en referencia a la violencia doméstica:

We should interpret a 'public' wrong, not as a wrong that injures the public, but as one that properly concerns the public, i.e. the polity as a whole. [...] What makes domestic abuse a public wrong is that, as we now recognize, it concerns us all, as a wrong in which we share: we must not leave the victim to pursue her own grievance, but must collectively pursue it with her or for her ${ }^{8}$.

A este respecto, no está de más reparar en que, acertadamente, Duff observa que, de acuerdo con esta misma comprensión del problema, el carácter "público" de una forma de comportamiento con significación criminal tiene que ser entendido como una implicación de su criminalización, y no, en cambio, como una razón para esta ${ }^{9}$. Esto quiere decir, más precisamente, que serían las razones (sustantivas) que sustentan la correspondiente decisión de criminalización las que determinan, en esa misma medida, la connotación "pública" de la forma de comportamiento así criminalizada, sin que tenga sentido alguno pretender identificar esta connotación con independencia de, y de manera previa a, esas mismas razones.

7 Duff, A., Sobre el castigo. Por una justicia penal que hable el lenguaje de la comunidad, Buenos Aires: Siglo XXI, 2015, p. 125. Véase en detalle Duff , A., Answering... op. cit, págs. 51 ss., 140 ss.

8 Duff , A., Answering... op. cit., pág. 141.

9 Duff , A., Answering... op. cit., pág. 142; también Duff, A., Sobre el castigo. Por una justicia penal que hable el lenguaje de la comunidad, Buenos Aires: Siglo XXI, 2015, pág. 125. 
Juan Pablo Mañalich R.

Así entendida, una decisión de criminalización fija un subconjunto de las condiciones de punibilidad de cuya satisfacción depende que una persona pueda quedar sometida a la imposición de una pena, en razón de resultar responsable de la realización de esa misma forma de comportamiento. Esto último introduce una referencia a uno de los aspectos más intrincados, a la vez que determinantes, de la obra de Duff, el cual ya fuera introductoriamente presentado, a saber: la distinción entre condiciones de la punibilidad y condiciones de la responsabilidad.

Que la respectiva decisión de criminalización solo fije algunas de las correspondientes condiciones de punibilidad (liability), en el sentido de "susceptibilidad al castigo", se explica por el hecho de que entre éstas también figuran algunas de naturaleza más bien general, en cuanto prima facie pertinentes tratándose de cualquiera forma de comportamiento criminal, con independencia de su fisonomía específica. En tal medida, cabe distinguir entre condiciones especiales y generales de la punibilidad, aun cuando esta distinción tendría que ser entendida, según Duff, como una de carácter gradual ${ }^{10}$. En cualquier caso, es claro que Duff recurre al concepto de liability para identificar, de manera congruente con el célebre análisis de las "relaciones jurídicas fundamentales" presentado por Hohfeld ${ }^{11}$, una posición pasiva de sujeción, definida por la susceptibilidad de padecer la imposición de una cierta consecuencia jurídica, cuya posición activa correlativa está constituida por la potestad detentada por quien está habilitado para imponer esa misma consecuencia jurídica. Esto explica que el concepto de liability aparezca ab initio desconectado de la especificidad de la pena qua consecuencia jurídica; tal como Duff lo hace explícito, cabe hablar de semejante sujeción en referencia al pago de un tributo, a la satisfacción de una pretensión indemnizatoria, al pago de una pensión

${ }^{10}$ Prima facie, en la medida en que se asuma, con Duff, que la distinción misma entre las provincias de la "parte general" y la "parte especial" sería asimismo gradual; véase Duff , A., Answering... op. cit, págs. 1 ss., 4.

${ }^{11}$ Hohfeld, W., Fundamental Legal Conceptions, New Haven y Londres: Yale University Press, 1919. págs. 35 ss., 50 ss. 
Responsabilidad, autoridad y democracia una exploración crítica ...

alimenticia, etc. ${ }^{12}$. Con ello, es recién por vía de especificación que se llega al concepto de criminal liability, que Duff identifica, más precisamente, con una sujeción a la imposición de "condena y castigo" (conviction and punishment), y que corresponde, stricto sensu, a lo que aquí habrá de entenderse por "punibilidad".

\section{II.2. Dos nociones de responsabilidad}

Es la especificidad de la consecuencia jurídica a cuya imposición una persona está expuesta lo que determina, a su vez, qué condiciones de responsabilidad tendrían que verse satisfechas para que esa misma persona en efecto quede sujeta a la imposición de aquélla. Aquí conviene reproducir literalmente la caracterización que Duff hace de la relación en que se encontrarían los conceptos de punibilidad y responsabilidad:

The relationship between liability and responsibility can be simply stated: responsibility is a necessary but not a sufficient condition of liability. I am liable to conviction or blame for $X$ only if I am responsible for $X$; but I can be responsible for $X$ without thus being liable ${ }^{13}$.

Esta comprensión de la relación en cuestión da pie a que Duff tematice el paso (argumentativo) que lleva de la adscripción de responsabilidad a la fundamentación de punibilidad como una transición "presuntiva" - o cabría decir también: derrotable-, en el sentido de que lo primero conducirá a la segundo a menos que el imputado logre esgrimir alguna "respuesta exculpatoria" que precisamente obstaculice esa misma transición ${ }^{14}$. Semejante respuesta exculpatoria habría de consistir en alguna eximente que (argumentativamente) funcione en la forma de una condición de justificación o una condición de excusa,

${ }^{12}$ Duff , A., Answering... op. cit., pág. 19.

${ }^{13}$ Ibídem, pág. 20.

${ }^{14}$ Ibídem, pág. 22. 
Juan Pablo Mañalich R.

que son las dos especies de eximente que Duff sistemáticamente agrupa bajo el concepto (estricto) de "defensa" (defence) $)^{15}$.

Aquí es crucial reparar en que, en estos términos, aquello de lo cual una persona puede resultar responsable consiste, stricto sensu, en la realización de los presupuestos objetivos (constitutivos del actus reus) y subjetivos (constitutivos del mens rea) del respectivo delito (offence), en el sentido de que

there is something for which the defendant must answer in court, on pain of being held criminally liable if she fails to offer an adequately exculpatory answer ${ }^{16}$.

En este sentido, entonces, las condiciones de la responsabilidad se comportan como condiciones positivas de la punibilidad, precisamente porque la comprobación de la satisfacción de esas condiciones conduce a la afirmación de punibilidad, a menos que ésta resulte suprimida por la concurrencia de alguna de aquellas eximentes que cuentan como condiciones de justificación o de excusa, esto es, como "defensas". En tal medida, la invocación de una defensa supone una asunción de responsabilidad por parte de la persona que, al mismo tiempo, niega -dadas las circunstancias constitutivas de la defensa respectivaque esa responsabilidad fundamente la correspondiente punibilidad ${ }^{17}$.

Esta comprensión de la relación en que se encontrarían los conceptos de responsabilidad y punibilidad es ciertamente problemática, desde ya porque a ella parece subyacer una confusión entre dos nociones - una sustantiva y otra procedimental- que pueden ser expresadas por el término "defensa" ${ }^{18}$. Lo que aquí interesa, empero, es observar

${ }^{15}$ En detalle al respecto Duff , A., Answering... op. cit, pág. 263 ss.

${ }^{16}$ Duff , A., Answering... op. cit, pág. 216.

${ }^{17}$ Ibídem, pág. 21.

${ }^{18}$ Véase Duarte, L., Allowing for Exceptions: A Theory of Defences and Defeasibility in Law., Oxford: Oxford University Press, 2015, pág. 239 ss., quien correctamente advierte que, en sentido sustantivo, una "defensa" se corresponde con una excepción, en tanto que, en sentido procesal, con una alegación esgrimida contra un cargo previamente formulado, siendo puramente contingente, empero, que una defensa en el primer sentido tenga que ser invo- 
Responsabilidad, autoridad y democracia una exploración crítica ...

en que el concepto de responsabilidad al que recurre Duff, para especificar el pretendido conjunto de condiciones necesarias, mas no suficientes, de la punibilidad, no es idéntico al concepto de responsabilidad al que él recurre cuando tematiza aquellas "condiciones para la rendición de cuentas", que fungirían como "precondiciones de la punibilidad"19. Que Duff recurra a una misma expresión -i.e., "condiciones de responsabilidad" - para designar aquellas condiciones que presuntivamente fundamentan la punibilidad, por un lado, así como aquellas precondiciones de las cuales depende que de hecho pueda ser tematizada la punibilidad, por otro, es algo que conspira seriamente contra la claridad de su discurso ${ }^{20}$. No está de más advertir, con todo, que Duff parece estar consciente de la ambigüedad que esa misma expresión adquiere a través del uso dual que él le da, cuando observa:

The trial is concerned, ultimately, with whether the defendant satisfies the conditions of criminal responsibility and liability for the alleged offence. But the possibility of bars to trial focuses our attention on conditions that must be satisfied if the trial itself is to be legitimate: these are in one sense conditions of criminal responsibility,

cada como una defensa en el segundo sentido. Aceptar esta distinción no supone, sin embargo, aceptar la muy problemática tesis, también sostenida por Duarte, de que la imposición de la respectiva consecuencia jurídica, especificada por la norma de que se trate, no tendría que entenderse asociada a la efectiva satisfacción de los presupuestos fácticos que conforman su supuesto de hecho, sino más bien a la afirmación o "comprobación" judicial de su satisfacción; ibid., pp. $246 \mathrm{~s}$. En tal medida, Duarte no reconoce espacio para la (inexorable) distinción entre la imposición sustantivamente correcta de la consecuencia jurídica en cuestión, por un lado, y la corrección procedimental de su imposición, por otro. Como ha demostrado Navarro (2014), p. 154 ss., no es acertado negar que la norma que establece la respectiva consecuencia jurídica pueda ser efectivamente aplicada en un caso en el cual esa misma norma no resulta aplicable, sin que eso obste a la posibilidad de reconocer que, entonces, la norma habrá sido mal aplicada.

${ }^{19}$ Duff, A., "Law, Language and Community: Some Preconditions of Criminal Liability”, Oxford Journal of Legal Studies 18, 1998, pág. 194.

${ }^{20}$ Véase al respecto Mañalich, op. cit., pág. 267 ss. 
Juan Pablo Mañalich R.

since they determine whether this defendant must answer for this alleged conduct before this court ${ }^{21}$.

Que Duff conceda que las precondiciones de la punibilidad constitutivas de condiciones para la rendición de cuentas pueden ser entendidas como condiciones de la responsabilidad criminal, "en un sentido" que ciertamente no coincide con aquel en que esa misma expresión es usada al comienzo del pasaje recién reproducido, sugiere la conveniencia de diferenciar las dos nociones. En efecto, Duff mismo sienta una base para tal diferenciación, cuando llama la atención acerca de la necesidad de no confundir el proceso de "responder $a$ un cargo criminal", por un lado, con el proceso de "responder por un delito", por otro ${ }^{22}$.

\section{II.3. La estructura relacional de la responsabilidad criminal}

Un aspecto especialmente importante de la contribución de Duff al debate contemporáneo acera de las condiciones de legitimación y deslegitimación de los regímenes de derecho penal consiste en su insistencia en la determinación irreductiblemente política de las posiciones ocupadas por quienes pueden llegar a intervenir en el proceso de activación de la responsabilidad jurídico-penal por la realización de un comportamiento dotado de significación criminal. El punto ha sido marcado con especial precisión por Harel, en el contexto de su defensa de la concepción triádico-relacional de la responsabilidad articulada por Duff ${ }^{23}$. La caracterización que éste ofrece de la estructura

${ }^{21}$ Duff , A., Answering... op. cit, pág. 181 (cursivas añadidas).

22 Ibidem, pág. 176.

${ }^{23}$ Harel, A., "The Triadic Relational Structure of Reponsibility: A Defence", en Cruft, R.; Kramer, M. y Reiff, M., 2011, pág. 103 ss.; para un intento de refutación de la caracterización duffiana de la "responsabilidad básica" como relacional, véase sin embargo Gardner (2011), pág. 87 ss., quien apoya su argumento en la concepción raziana de la autoridad como servicio, procurando demostrar que las razones que sustentan un reconocimiento de autoridad práctica no serían relacionales (ibid., pág. 93 ss.). 
Responsabilidad, autoridad y democracia una exploración crítica ...

triádica que exhibiría, en general, toda relación de responsabilidad queda suficientemente plasmada en el siguiente pasaje:

I am responsible for $X$, to $S$-to a person or body who has the standing to call me answer for $\mathrm{X}$. I am also responsible for $\mathrm{X}$ to $\mathrm{S}$ as $\Phi$-in virtue of satisfying some normatively laden description that makes me responsible [...] for $\mathrm{X}$ to $\mathrm{S}$. To be responsible is to be answerable; answerability is answerability to a person or body who has the right or standing to call me to account; and I am thus answerable in virtue of some normatively laden description, typically a description of a role, that I satisfy ${ }^{24}$.

Esta comprensión de la estructura de las relaciones de responsabilidad está fundada en la adopción de lo que cabría catacterizar como un "giro pragmático": la responsabilidad de una persona $\mathrm{P}$ por X es una responsabilidad que $\mathrm{P}$ tiene, por $\mathrm{X}$, ante $\mathrm{S}$, precisamente porque ser responsable de $\mathrm{X}$ consiste en poder ser llamado a responder, por alguien, de $\mathrm{X}^{25}$. Lo que aquí interesa, empero, es la consideración de que $\mathrm{P}$ sólo podrá ser responsable ante $\mathrm{S}$ por $\mathrm{X}$ en la medida en que $\mathrm{P}$ exhiba el estatus de $\Phi$. Tratándose de la responsabilidad jurídico-penal de $\mathrm{P}$ por $\mathrm{X}$ ante $\mathrm{S}$, cuando $\mathrm{X}$ consiste en la realización de una forma de comportamiento criminalmente significativa, Duff entiende que el estatus de $\Phi$ debe ser paradigmáticamente identificado con la condición de ciudadano de una comunidad política democráticamente organizada ${ }^{26}$, de modo tal que el lugar de $\mathrm{S}$ ha de ser ocupado, correspondientemente, por esa misma comunidad política.

Harel sostiene que el mejor argumento para sustentar esta caracterización relacional de la responsabilidad criminal consiste en el "argumento del autogobierno" 27 , en el sentido de que semejante

${ }^{24}$ Duff , A., Answering... op. cit, pág. 23.

${ }^{25}$ Acerca de la estructura triádica de las relaciones de imputación qua relaciones de atribución de responsabilidad, véase Mañalich, J. P., "El concepto de acción y el lenguaje de la imputación". DOXA 35, 2012, págs. 663 ss., 676 ss., con referencias ulteriores.

${ }^{26}$ Duff , A., Answering... op. cit, págs. 43 ss., 49 ss.,

${ }^{27}$ Harel, A., The Triadic... op. cit., pág. 115 ss. 
Juan Pablo Mañalich R.

estructuración de la responsabilidad resguardaría "la libertad de los participantes en la unidad de responsabilidad relevante para gobernarse a sí mismos" 28 . La condición de posibilidad de esto último, sin embargo, es que tal concepción de la responsabilidad sea complementada por una concepción que especifique los criterios de reconocimiento de la "unidad de responsabilidad relevante", que aquí está constituida por la respectiva comunidad política. Pues de lo contrario sería imposible demarcar, de un modo que logre sortear la objeción de la circularidad, el foco y el alcance de las responsabilidades susceptibles de ser activadas en el nivel de la propia comunidad política, sin que esas responsabilidades colapsen con otras pertenecientes a unidades escalarmente diferentes ${ }^{29}$.

Por supuesto, este no es el lugar para explorar este último problema. Pero sí cabe remarcar un aspecto de la concepción de Duff que resulta de especial importancia en la construcción de la imagen -fuertemente idealizada- de un derecho penal democrático. Este aspecto concierne a la centralidad que, en el marco de esa concepción, adquiere el estatus de ciudadano como estatus que identifica el paradigma de persona susceptible de ser hecha jurídico-penalmente responsable $^{30}$. Esto ha dado lugar a que se dirijan objeciones referidas a la dificultad que su tesis enfrentaría a la hora de justificar, entre otros, el llamado a responder que una comunidad política puede dirigir a un extranjero que ha quebrantado el derecho de aquélla ${ }^{31}$, así como a la hora de fundamentar, con alguna plausibilidad, tanto el reconocimiento de jurisdicción universal sobre crímenes internacionales de

${ }^{28}$ Ibídem, pág. 115.

${ }^{29}$ Ibidem, pág. 119 ss.

${ }^{30}$ En este sentido ya Kindhäuser, U. y Mañalich, J. P., Pena y culpabilidad en el Estado democrático de derecho, 2a ed., Montevideo y Buenos Aires: BdF, 2011, págs. 118 ss., 134 ss.

${ }^{31}$ Véase por ejemplo Chehtman, A., Fundamentación filosófica de la justicia penal extraterritorial, Madrid, Barcelona, Buenos Aires y San Pablo: Marcial Pons, $178 \quad$ 2013, pág. 124 ss. 
Responsabilidad, autoridad y democracia una exploración crítica ...

particular gravedad como la jurisdicción complementaria susceptible de ser ejercida, bajo determinadas condiciones, por la Corte Penal Internacional ${ }^{32}$.

En relación con esto último, Duff ha advertido la necesidad de introducir una cualificación de su punto de vista ${ }^{33}$, favoreciendo la hipótesis de que, en este mismo ámbito, la responsabilidad en cuestión se activaría no ante alguna comunidad política particular, sino ante la humanidad toda qua comnidad moral (mas no política) ${ }^{34}$. Pero es a propósito del primer punto que la concepción de Duff muestra su mayor virtud. Pues en contra de la denuncia de que, en vez de una apelación a la autonomía política de los ciudadanos de una democracia, la pretensión de vinculación exhibida por las normas de comportamiento cuyo quebrantamiento adquiere significación criminal tendría que sustentarse en nada más que la garantía de la autonomía privada que su reforzamiento jurídico-penal ofrecería ${ }^{35}$, la insistencia de Duff en que un derecho penal legítimo es un derecho penal de ciudadanos hace posible tematizar, y no ocultar, el problema que aquí se presenta. Se trata, en efecto, del carácter problemático del llamado a responder que una comunidad política puede dirigir a un extranjero ${ }^{36}$, así como en general a personas que -como los menores de edad- no están habilitadas para participar plenamente en el ejercicio de autodeterminación colectiva a través del cual una comunidad democrática puede

${ }^{32}$ Chehtman, op. cit, , p. 181 ss. No está de más apuntar aquí que, en el desarrollo de su argumento concerniente a la fundamentación de la competencia penal extraterritorial, Chehtman hace suya la concepción raziana de la autoridad como servicio; véase Chehtman, op. cit., págs. 203 ss., 208 ss.

${ }^{33}$ Duff , A., Answering... op. cit, pág. 55 ss.

${ }^{34} \mathrm{Al}$ respecto Duff, A., "Authority and Responsibility in International Criminal Law", en: Besson, S. y Tasioulas, J., The Philosophy of International Law, Oxford y Nueva York: Oxford University Press, 2010, págs. 589 ss., 597 ss. Para una concepción de los crímenes contra la humanidad así orientada, véase asimismo Mañalich, J. P., Terror, pena y amnistía, Santiago: Flandes Indiano, 2010, pág. 12 ss.

${ }^{35}$ Así Silva Sánchez, J., "Prólogo", en: Kindhäuser, U. y Mañalich, J. P., 2011, págs. xiii-xxii. p. xviii ss.

${ }^{36} \mathrm{Al}$ respecto Mañalich, Terror... op. cit., pág. $93 \mathrm{~s}$. 
Juan Pablo Mañalich R.

poner en vigor, revisar o bien suprimir pautas de comportamiento correcto que, en cuanto razones dotadas de autoridad, hayan de resultar perentoriamente vinculantes, con independencia de su contenido ${ }^{37}$.

Aquí basta con observar que, en contra de lo sugerido por Chehtman, el recurso de Duff a la noción de huésped, para así caracterizar la posición que ocupa una persona que, sin ser ciudadano, puede quedar sometida a la aplicación de la legislación penal del Estado en cuyo territorio ella se encuentra ${ }^{38}$, no trae consigo el riesgo de un regreso a "una concepción territorial" del fundamento de la jurisdicción del respectivo Estado para hacer aplicable su legislación penal ${ }^{39}$, concepción que Duff efectivamente rechaza ${ }^{40}$. Pues si bien es correcto decir que la caracterización de una persona como un huésped se ve "determinada espacialmente", dado que, en efecto, "[y]o soy un huésped en la casa de Pedro sólo cuando estoy físicamente en su casa" 41 , de ello no se sigue que esa misma caracterización sea exclusivamente relativa a la situación espacial de la primera de las dos personas. Que alguien sea el huésped de otro significa, correlativamente, que éste cuenta como el anfitrión de aquél. La descripción de la casa en que Alejandro se encuentra como "la casa de Pedro" no se limita a especificar el lugar en que se encuentra Alejandro en exclusiva referencia a la ubicación de ese lugar en el espacio ${ }^{42}$, sino que al mismo tiempo lo específica a través de una atribución de una cierta titularidad sobre ese lugar a Pedro. Es justamente la normatividad propia de la relación en la cual se encuentran un huésped y su anfitrión lo que Duff explota en su asimilación metafórica de la posición del extranjero o foráneo,

${ }^{37} \mathrm{Al}$ respecto Mañalich, J. P., "Pena y ciudadanía", en: Kindhäuser, U. y Mañalich, J. P., 2011, pág. 123 ss.

${ }^{38}$ Véase Duff , A., Answering... op. cit, pág. 54 s.; también Duff, A., "Responsibility, Citizenship, and the Criminal Law", en: Duff, A. y Green, S., 2011, pág. 141 ss.

${ }^{39}$ Chehtman, op. cit., pág. $126 \mathrm{~s}$.

${ }^{40}$ Véase Duff , A., Answering... op. cit, pág. 44 ss.

${ }^{41}$ Chehtman, op. cit., pág. 127.

${ }^{42}$ Lo cual dependerá, por lo demás, de que la expresión "la casa de Pedro" no sea referencialmente ambigua, esto es, de que Pedro sólo tenga una casa, y no varias. 
en cuanto no-ciudadano, a la posición de un huésped. Y aquí no está de más advertir que uno de los aspectos de esa normatividad distintiva consiste en la asimetría de las posiciones de anfitrión y de huésped en lo tocante a la titularidad sobre el respectivo lugar o territorio, lo cual quiere decir aquí: justamente en lo tocante a las reglas que rigen en el ámbito espacial así delimitado.

Con ello, la solución del problema ciertamente no pasa por negar la plausibilidad de la fundamentación de un reproche de culpabilidad dirigido a una persona que no exhibe el estatus de ciudadano del respectivo Estado, sino más bien por articular ese reproche de un modo que refleje la distancia que separa a esa persona del paradigma de persona jurídico-penalmente responsable, que es la persona políticamente habilitada para tomar parte en la producción de las normas cuyo seguimiento leal es recíprocamente esperado de y por quienes, en tal medida, resultan vinculados por reglas que se dan a sí mismos.

\section{Legitimidad y autoridad}

\section{III.1. Comunitarismo liberal como horizonte de legitimidad}

Según ya se sostuviera, la importancia de la tematización diferenciada de lo que Duff identifica como precondiciones de la punibilidad radica en que de la satisfacción de esas precondiciones depende la legitimidad del proceso judicial en el marco del cual ella pueda ser llamada a responder. La implicación ético-política que esto tendría es formulada en los términos siguientes:

[T] he court which tries the defendant must have the authority to call her to account, on behalf of a citizen body to whom she is answerable $e^{43}$.

La legitimidad del llamado a responder que un tribunal puede dirigir a una persona depende, observa Duff, de la satisfacción de dos

${ }^{43}$ Duff, A., Law, Language... op. cit., pág. 196. 
Juan Pablo Mañalich R.

condiciones que él caracteriza como "morales", a saber: en primer lugar, que sobre el acusado efectivamente recayera una obligación de obedecer el derecho presuntamente quebrantado por él; y en segundo lugar, que el respectivo tribunal o bien aquellos a cuyo nombre este habla cuenten con la legitimidad suficiente para dirigir ese llamado a responder ${ }^{44}$.

Duff favorece una comprensión de las condiciones de legitimidad del llamado a responder que un tribunal puede dirigir a una persona que descansa en una apelación especialmente fuerte al concepto de comunidad:

For one account of the moral conditions of the obligation to obey the law, and of being answerable through the courts, is expressed in terms of community. The defendant is obligated to obey the law in virtue of his membership of a community whose law it is; and he is answerable through the courts to his fellow members of the community for his alleged breaches of that law. On this account, our questions are questions about the conditions for the existence, and for membership, of a community of the appropriate kind ${ }^{45}$.

El tipo de comunidad que, según Duff, puede dar lugar a una forma de vida en cuyo seno lleguen a satisfacerse tales condiciones de legitimidad es el de una "comunidad liberal", integrada por ciudadanos cuya vida en común "está estructurada por valores liberales nucleares tales como la autonomía, la libertad, la privacidad y el pluralismo", y que se ve "informada por una concepción de cada uno como conciudadanos" que toman parte en "la empresa cívica compartida" 46 . Si bien esta puesta en relación de las tradiciones del liberalismo y del comunitarismo ha despertado perplejidad en algunos de sus lectores ${ }^{47}$, el propósito de

${ }^{44}$ Duff, A., Law, Language, op. cit., pág. 196.

45 Ibidem, pág. 197.

${ }^{46}$ Duff , A., Answering... op. cit., pág. 11.

${ }^{47}$ Destacadamente Gargarella, R., Castigar al prójimo, Buenos Aires: Siglo XXI, 2016, págs. 165 ss., 172 ss., quien atribuye a Duff un "duro rechazo al comunitarismo" (ibid., pág. 173), a la vez que caracteriza su postulación del modelo de una comunidad liberal como una "noción que parece difícil de comprender" (ibid., pág. 179). Probablemente, la dificultad en parte radique en que Gargarella parece asignar un sentido a la apelación que Duff hace 
Responsabilidad, autoridad y democracia una exploración crítica ...

Duff consiste en demostrar la necesidad de proyectar su concepción (idealizada) de una forma de vida democrática a través de un modelo de "comunidad liberal" 48 , sustentado en una defensa de la primacía tanto metafísica como normativa del "nosotros" frente al "yo" 49

Ciertamente, Duff no entiende esta primacía como fundante de una relación de subordinación de los individuos a la respectiva comunidad, sino más bien en términos de que el punto de partida para la reflexión acerca de cómo debería estructurarse la correspondiente forma de vida compartida no puede sino estar constituido por los "individuos en comunidad", esto es, por "individuos que ya se reconocen a sí mismos como viviendo en comunidad con otros" ${ }^{50}$. Esto se traduce en que en la base de la experiencia ético-política de esos mismos individuos tendríamos que encontrarnos no con su elección de formar parte de una posible asociación, sino con el reconocimiento de su co-pertenencia (controvertible y, eventualmente, revisable) a la comunidad respectiva ${ }^{51}$.

En este sentido, una comunidad liberal à la Duff es una cuyos miembros muestran un compromiso práctico con la sustentación de una forma de vida que realiza los valores de la autonomía, la libertad y la privacidad. Y solo una forma de vida así practicada, piensa Duff, puede dar lugar a que el lenguaje del derecho penal llegue a constituirse en un lenguaje que los ciudadanos de esa comunidad política puedan reconocer como uno que habla su propia voz.

a la "pesadilla macintyreana" que de hecho no coincide con el sentido que Duff le asigna. Pues por esa vía Duff no intenta advertir sobre "los peligros del comunitarismo", sino más bien contrarrestar la sugerencia de que, en las condiciones de las modernas democracias liberales, no sería posible la sustentación de formas de vida compartida que hagan posible el desacuerdo sobre un trasfondo de acuerdos implícitamente practicados; véase especialmente Duff, A., Law, Language, op. cit., pág. 201 ss.

${ }^{48}$ Detalladamente Duff, A., Punishment, Communication, and Community, Oxford y Nueva York: Oxford University Press, 2001, pág. 35 ss.; también Duff , A., Answering... op. cit., págs. 49 ss., 191 ss.

${ }^{49}$ Duff, A., Punishment... op. cit., pág. 51 ss.

${ }^{50}$ Duff, A., Punishment... op. cit., pág. 52.

${ }^{51}$ Ibidem, pág. 53. 
Juan Pablo Mañalich R.

\section{III.2. "Prohibiciones" versus "declaraciones"}

Una implicación de semejante configuración idealizada de un derecho penal democrático consistiría, según Duff, en el modo en que habría que fundamentar el carácter potencialmente vinculante $\mathrm{u}$ obligante del derecho cuyo quebrantamiento puede resultar delictivo. A este respecto, Duff introduce una distinción entre dos posibles concepciones de las reglas que especifican las condiciones de incorrección (wrongness) de aquellas formas de comportamiento de cuya realización una persona puede ser hecha criminalmente responsable, a saber: la distinción entre una concepción que las entendería como "prohibiciones" y otra que las entendería como "declaraciones" 52 . Por esta vía, Duff persigue defender la tesis de que sólo la segunda concepción sería congruente con la imagen del derecho penal democrático propio de una comunidad liberal.

Lo que Duff entiende por "prohibición" se corresponde, sin más, con el concepto de norma que es propio de un modelo imperativista, que se distingue por la postulación de una supuesta obligación de "obedecer al derecho" como fuente última del carácter vinculante de los estándares de comportamiento cuyo quebrantamiento puede resultar delictivo. En la formulación que Duff mismo provee para semejante concepción:

It seems natural to say that the criminal law 'prohibits' conduct it defines as criminal. We supposedly have an obligation to obey the law and may be punished if we disobey it; and to obey the law is to refrain from doing what it prohibits, because it is legally prohibited $^{53}$.

Acertadamente, Duff evita identificar tal comprensión imperativista del concepto de regla con aquella versión de imperativismo -en tal medida: "híbrido"- que, en la senda de Bentham y Austin, se distingue por explicar la obligatoriedad del derecho a partir de su

${ }^{52}$ Ibídem, pág. 56 ss.

$184 \quad{ }^{53}$ Ibidem, pág. 56. 
Responsabilidad, autoridad y democracia una exploración crítica ...

coercitividad $^{54}$. Pues si el derecho ha de exhibir genuina normatividad, observa Duff, la fuerza vinculante de una regla jurídica no puede hacerse depender de la amenaza de imposición de alguna sanción para el caso de su quebrantamiento ${ }^{55}$. Al mismo tiempo, sin embargo, Duff se muestra convencido de que, siendo exhaustiva la disyuntiva entre validar una explicación imperativista de la obligatoriedad de las normas del derecho penal, por un lado, y renunciar a la idea de que el derecho penal pueda proveer "nuevas razones para la acción", por otro, lo correcto sería abrazar este último camino. Pues

how odd it would be for a person to refrain from murder, not because she saw it to be wrongful independently of the criminal law, but from respect for the law that criminalises it; what kind of person would be willing, independently of the law, to attack another's life, but yet so respectful of the law's authority that she would refrain from the attack because the law prohibited it? ${ }^{56}$.

Aquí Duff está negando que el derecho penal pueda proveer de razones para la acción ${ }^{57}$. Tomada en sí misma, esta afirmación (negativa)

${ }^{54}$ Para la correspondiente distinción entre imperativismo puro e imperativismo híbrido (o mixto), véase Mañalich, J. P., "Reglas primarias de obligación. Las 'reglas del derecho penal' en El Concepto de Derecho de H.L.A. Hart", Zeitschrift für Internationale Strafrechtsdogmatik 1/12, 2012, disponible en: http://www.zisonline.com/dat/artikel/2012_11_716.pdf., pág. 571 s., nota 7.

${ }^{55}$ Duff , A., Answering... op. cit , pág. 85. Nótese, en todo caso, que para un modelo de imperativismo híbrido à la Bentham y Austin no es la amenaza de la imposición de una sanción, sino la predictibilidad de su imposición lo que, stricto sensu, fundamentaría la obligatoriedad de la evitación de la forma de comportamiento a cuya realización está asociada la imposición de tal sanción; véase Hart, H. L. A., Essays on Bentham, Oxford: Clarendon Press, 1982 pág. 132 ss.

${ }^{56}$ Duff , A., Answering... op. cit, pág. $85 \mathrm{~s}$.

${ }^{57}$ La noción de provisión de razones para la acción aquí empleada se corresponde con lo que Enoch caracteriza como una provisión "robusta" de razones para la acción, diferenciada de las nociones de una provisión "puramente epistémica" y de una provisión "meramente gatillante" de razones para la acción; véase Enoch, D., "Reasong-Giving and the Law", en: Green, 
Juan Pablo Mañalich R.

es irrestrictamente correcta, lo cual se deja formular en términos del análisis que Hart ofrece de las así llamadas "reglas del derecho penal": stricto sensu, por "derecho penal" puede entenderse la praxis institucional de producción y aplicación de normas de sanción, las cuales deben ser entendidas como reglas secundarias de adjudicación que especifican las sanciones susceptibles de ser impuestas y ejecutadas como consecuencia del quebrantamiento imputable de algún conjunto de normas de comportamiento, las cuales consisten, a su vez, en reglas primarias de obligación ${ }^{58}$. Con ello, la clarificación del punto pasa por una desambiguación de la preposición "de" en cuanto componente (contraído) de la expresión "reglas del derecho penal". Las correspondientes normas de comportamiento son reglas "del" derecho penal, mas no porque formen parte del respectivo ordenamiento jurídico-penal, sino más bien porque ellas constituyen su objeto de referencia: se trata de reglas cuyo específico criterio (institucionalizado) de reconocimiento consiste en el hecho de que ellas se encuentran -íntegra o fragmentariamente- reforzadas por un determinado conjunto de normas de sanción, cuyo estatus de tales es, a su vez, pragmáticamente dependiente del hecho de que su respectiva condición de aplicación está constituida por el quebrantamiento de un estándar jurídico de comportamiento correcto. Esto es lo que subyace a la célebre tesis de Binding, el padre de la teoría de las normas del derecho penal en el discurso de la doctrina alemana, en cuanto a que las normas punitivamente reforzadas por la legislación penal tendrían el carácter de normas de derecho público general ${ }^{59}$.

L. y Leiter, B., Oxford Studies in Philosophy of Law, vol. 1. Oxford y Nueva York: Oxford University Press, 2011, pág. 3 ss.

${ }^{58} \mathrm{Al}$ respecto Mañalich, "Reglas primarias..." op. cit., págs. 578 ss., 581 s., con referencias ulteriores.

${ }^{59}$ En detalle al respecto Mañalich, J. P., "Normas permisivas y deberes de tolerancia", Revista Chilena de Derecho 41, 2014, pág. 500 ss. 
Responsabilidad, autoridad y democracia una exploración crítica ...

\section{III.3. Mala in se y mala prohibita}

Pero la caracterización recién ofrecida ciertamente no es compartida por Duff. Pues este hace suya una comprensión de la "autoridad del derecho penal" según la cual sería profundamente distorsionador pretender dar cuenta del catálogo más tradicional de las decisiones de criminalización plasmadas en la parte especial del correspondiente ordenamiento jurídico-penal, que son aquellas que fijan las condiciones de punibilidad de los delitos constitutivos de mala in se, como un catálogo de decisiones de reforzamiento punitivo de normas jurídicas con fuerza obligante ${ }^{60}$. Duff sostiene, antes bien, que semejante caracterización sólo resulta pertinente y verosímil tratándose de delitos constitutivos de mala prohibita, mas no tratándose de aquellos que cuentan como especies de mala in $s e^{61}$.

Esta última distinción adquiere importancia superlativa en la concepción general del derecho que habita la obra de Duff, y es introducida por éste en su esfuerzo por articular y defender una forma notoriamente cualificada -y restringida- de "legalismo moral", posición según la cual la incorrección moral de una forma de comportamiento sería una buena razón para la criminalización de ésta ${ }^{62}$, en el sentido de que tal incorrección no representa meramente una "condición necesaria" para la correspondiente decisión de criminalización, sino propiamente su "foco" 63 . A este respecto, el propósito de Duff consiste en demostrar que, bajo ciertas condiciones, tanto la criminalización de los delitos constitutivos de mala in se como la de aquellos constitutivos de mala prohibita puede satisfacer la exigencia planteada por el legalismo moral.

${ }^{60}$ Duff, A., Punishment... op. cit., pág. 57 ss.

${ }^{61}$ Véase Duff, A., Punishment... op. cit. pág. 64 ss.; y especialmente Duff, A., Answering... op. cit, págs. 85 ss., 89 ss., 166 ss., 220 ss.

${ }^{62}$ Duff , A., Answering... op. cit, págs. 47 s., 84 ss. Una versión considerablemente menos cualificada $-\mathrm{y}$, consiguientemente, menos restringida- de legalismo moral como "doctrina de criminalización" es defendida en Moore, M., Placing Blame, Oxford y Nueva York: Oxford University Press, 1997, pág. 639 ss.

${ }^{63}$ Duff, A., Answering... op. cit, pág. 80. 
Juan Pablo Mañalich R.

Para esto, Duff se ve en la necesidad de revisar los términos en que la distinción entre una y otra categoría es tradicionalmente entendida. De acuerdo con su comprensión tradicional, en efecto, la distinción operaría contraponiendo formas de comportamiento delictivo incorrectas intrínsecamente o "por sí mismas", por un lado, y formas de comportamiento delictivo cuya incorrección sería meramente resultante de su criminalización, por otro. Bajo esta comprensión, es claro que lo que cuenta como malum prohibitum no puede llegar a ser criminalizado en razón de su incorrección, pues el único sentido en que cabe predicar incorrección de tal forma de comportamiento es un sentido en que esa incorrección es superviniente a su criminalización. Ergo, el legalismo moral no se vería respetado por semejante decisión de criminalización. ${ }^{64}$ Esta dificultad sólo se disipa, ahora bien, si son distinguidos los conceptos de criminalización y regulación, en cuanto expresivos de dos tipos de acción legislativa:

by distinguishing the two legislative questions, we can now see how conduct that is not wrongful prior to or independently of its legal regulation can be wrongful prior to or independently of its criminalisation -and thus how legal moralists can see good reason to criminalise it ${ }^{65}$.

De este modo, la criminalización de formas de comportamiento constitutivas de mala prohibita logra satisfacer la exigencia planteada por el legalismo moral, en la medida en que la incorrección de aquéllas sólo resulta dependiente de la regulación en cuya contravención consiste la respectiva forma de comportamiento, mas no de la correspondiente decisión de criminalización. Y esto ofrece la clave, entonces, para especificar lo que Duff correlativamente entiende como delitos constitutivos de mala in se, a saber:

wrongs that can be identified as wrong, independently not only of the criminal law that defines them as crimes, but of legal regula-

${ }^{64}$ Duff, A., Answering... op. cit., pág. 89 s.

${ }^{65}$ Ibídem, pág. 91. 
Responsabilidad, autoridad y democracia una exploración crítica ...

tion more generally: they would be wrong even if no part of the law took any interest in them ${ }^{66}$.

Si bien esta definición resulta lo suficientemente ambigua, en razón del uso de "identificar", como para poder resistir tanto una interpretación en clave ontológica como una en clave epistemológica, es contextualmente claro que Duff asume la primera interpretación: la regulación de los delitos constitutivos de mala in se sería meramente recordatoria de la existencia de razones preexistentes para la evitar la realización de la respectiva forma de comportamiento ${ }^{67}$. Pues bajo la premisa de que las razones que el derecho penal nos ofrece para abstenernos de hacer aquello que ha sido criminalizado han de ser precisamente "las razones que justifican la demanda de que nos abstengamos de ello", Duff observa que, tratándose de mala in se, tales razones "conciernen a la incorrección pre-jurídica" de la forma de comportamiento en cuestión ${ }^{68}$. Es justamente esta postulación de semejante incorrección pre-jurídica lo que justificaría, según Duff, que las reglas que definen las formas de comportamiento cuya realización es constitutiva de malum in se tengan que ser entendidas como "declaraciones", y no como "prohibiciones"69. En sus propias palabras:

If the law is to reflect those reasons, and the values from which they flow, its definitions of central mala in se must thus be understood as declarations, rather than prohibitions. Its role is not make wrong what was not already wrong, but to declare that these pre-legal wrongs are public wrongs $[\ldots]^{70}$.

${ }^{66}$ Ibídem, pág. 89.

${ }^{67}$ En la terminología de Enoch, op. cit. pág. 4, se trataría de un modo de provisión "puramente epistémica" de razones para la acción.

${ }^{68}$ Duff, A., Answering... op. cit., pág. 86.

${ }^{69}$ Duff, A., Answering... op. cit., pág. 86 s. Como es obvio, lo que Duff entiende por "prohibición" resulta asimismo comprensivo de reglas cuyo operador o carácter deóntico no sea el de la prohibición, sino el del requerimiento, esto es, reglas que puedan fundamentar deberes de ejecutar acciones de cierto tipo. Véase Mañalich, J. P., Norma, causalidad y acción, Madrid, Barcelona, Buenos Aires y San Pablo: Marcial Pons, 2014, pág. 17 ss.

${ }^{70}$ Duff, A., Answering... op. cit., pág. 86. 
Juan Pablo Mañalich R.

La manera en que Duff articula esta distinción entre los conceptos de prohibición y declaración, empero, es altamente problemática. Pues el recurso a la noción de declaración que Duff favorece se orienta justamente a negar que la puesta en vigor de una regla que fija la específica incorrección de una forma de comportamiento cuya realización contaría como malum in se pueda ser plausiblemente entendida como generativa de una razón para la acción. Esto equivale a negar que, en este mismo ámbito, el derecho pueda exhibir una autoridad propiamente normativa, entendida como la capacidad para generar razones autoritativas. Que Duff sostenga este punto de vista se explica, más allá de su compromiso con la variante cualificada de legalismo moral, ya reseñada, por una insuficiente consideración del sentido preciso en que cabe identificar una regla de obligación con una razón para la acción.

\section{4. Las normas como razones externas para la acción}

El problema está en que Duff parece no advertir la necesidad de diferenciar una interpretación internista y una interpretación externista del concepto de razón para la acción ${ }^{71}$, asumiendo, antes bien, que el único sentido en que cabría hablar de una regla jurídica como constitutiva de una razón para la acción sería el primero. Esto mostraría, empero, cuán implausible sería, tratándose de la especificación de delitos que cuentan como mala in se, que éstos sean entendidos como contravenciones de normas dotadas de autoridad jurídica. Pues tal como ya se anticipara, Duff se pregunta, con perplejidad, lo siguiente:

how odd it would be for a person to refrain from murder, not because she saw it to be wrongful independently of the criminal law, but from respect for the law that criminalises it; what kind of person would be willing, independently of the law, to attack

${ }^{71}$ Véase Von Wright, G. H., Practical Reason, Oxford: Basil Blackwell, 1983, p. $53 \mathrm{~s}$. Al respecto, véase Mañalich, J. P., "La exculpación como categoría del razonamiento práctico". InDret 1/2013, 2013, disponible en: http://www. indret.com/pdf/944.pdf., pág. 5 ss. 
Responsabilidad, autoridad y democracia una exploración crítica ...

another's life, but yet so respectful of the law's authority that she would refrain from the attack because the law prohibited it? ${ }^{72}$.

La extrañeza que, de acuerdo con Duff, despertaría la sugerencia de que una persona podría llegar a abstenerse de perpetrar un asesinato por el respeto que pudiera ameritar una regla que prohibiera matar a otro ser humano, resulta del hecho de que, al hablar de ese modo, uno estaría sugiriendo que el sentido en que esa regla se presenta como una razón para omitir la acción respectiva es el propio de una razón "interna", esto es, una razón que efectivamente integra la base motivacional del agente respectivo ${ }^{73}$. Esto desconoce, sin embargo, que la pretensión de autoridad que es propia del derecho determina el carácter heterónomo del efecto vinculante de las normas jurídicas como razones para la acción, lo cual significa que el hecho de que una norma jurídica exhiba validez no implica en modo alguno que al mismo tiempo exhiba eficacia, esto es, que sea efectivamente "practicada" por parte de sus destinatarios.

La implicación de semejante comprensión "externista" del modo en que una norma puede fungir como una premisa práctica queda ilustrada en la siguiente observación de Von Wright, ofrecida en el contexto de su caracterización de las normas -qua "reglas prescriptivas"- como "desafíos (simbólicos)" para la acción:

Challenges I shall call outer or external reasons for action. Unlike internal reasons, challenges are contingently, and not necessarily, reasons. This means the following: Even though an agent recognizes the challenge and has learnt or otherwise knows how to respond to it, he need not acknowledge it as a reason for him to act upon. External reasons can thus be said to "exist" in two different senses. As instituted and presented to members of a community they exist,

${ }^{72}$ Duff, A., Answering... op. cit., pág. $85 \mathrm{s.}$

${ }^{73}$ Fundacional para la defensa de una concepción internista de las razones para la acción, Williams, B., Moral Luck, Cambridge: Cambridge University Press, 1982, pág. 101 ss. Para la defensa de una tesis "externista", véase Parfit, D., On What Matters, vol. I., Oxford y Nueva York: Oxford University Press, 2011, págs. 31 ss., 43 ss., 58 ss. 
Juan Pablo Mañalich R.

so to speak, "objectively". As acknowledged by individual agents as reasons for their acting they exist "subjectively". Their subjective existence cannot be inferred, in the individual case, from their objective existence ${ }^{74}$.

Así, que una norma exhiba el estatus de una razón "objetivamente existente" significa que su fuerza motivacional como premisa práctica no se encuentra per se asegurada, sino que depende de que esa misma norma sea "subjetivamente reconocida" como tal por su respectivo destinatario. De esto se sigue, a contrario sensu, que el solo hecho de que una determinada acción no haya sido omitida o no haya sido ejecutada en una situación en la cual una norma fundamentaba el deber de ejecutar u omitir tal acción, sirve de base para concluir, en la forma de un argumento ("destructivo") en modus tollendo tollens ${ }^{75}$, que la respectiva inferencia práctica en efecto no tuvo lugar, esto es: que esa norma no llegó a ser subjetivamente reconocida como premisa vinculante.

La relevancia de la distinción así reformulada se hace patente una vez que se advierte la especificidad del derecho -y en rigor: del derecho penal- como contexto de razonamiento práctico, el cual, en contraste con lo que cabría llamar "psicología del sentido común"76, se encuentra definido por lo que Binding aptamente caracterizara como una "psicología esotérica"77. Mientras la psicología del sentido común tiende a asumir que, en el caso normal, una persona ejecuta u omite una acción por las razones con las cuales cuenta para ejecutar u omitir esa acción, la imputación jurídico-penal reconoce como su situación

${ }^{74}$ Von Wright, op. cit., pág. 54.

${ }^{75}$ Cuya estructura es la siguiente:

$\mathrm{Si}$ (es el caso que) $p$, entonces (es el caso que) $q$; no (es el caso que) $q$; entonces, no (es el caso que) $p$.

${ }^{76}$ Véase Godfrey-Smith, P., "Folk Psychology as a Model" en: Philosopher's Imprint 5, n. ${ }^{\circ}$ 6, 2005 disponible en: www.philosophersimprint.org/005006/. passim.

${ }^{77} \mathrm{Al}$ respecto Mañalich, J. P. "La exculpación..." op. cit., pág. 6 s., con referencias ulteriores. 
Responsabilidad, autoridad y democracia una exploración crítica ...

específica de pertinencia aquella en la cual el agente no omite o no ejecuta aquella acción para cuya omisión o ejecución cuenta con una razón (jurídicamente) perentoria, constituida por la respectiva norma de prohibición o de requerimiento. De ahí que el contexto para tal imputación quede determinado por la constatación de que la razón por la cual el agente tenía que omitir o ejecutar una acción determinada de hecho no lo motivó a omitirla o ejecutarla, o en la terminología de von Wright: que la razón objetivamente instituida no fue subjetivamente reconocida como eficaz por el agente.

Con ello, el objeto del reproche jurídico-penal de culpabilidad admite ser redefinido en el sentido de que al autor se reprocha no haber convertido la norma en motivo, a pesar de haber sido posible y exigible, para él, tal motivación con arreglo a la norma ${ }^{78}$. Así, y en la medida en que la aplicación del derecho (penal) opera sobre la premisa de que la respectiva norma vale como razón para la acción -esto es, que su destinatario cuenta, eo ipso, con una razón perentoria para omitir o ejecutar la acción respectiva-, para la eventual imputación de su quebrantamiento sólo interesa la cuestión de si el destinatario habría podido dar seguimiento a la norma, bajo la hipótesis de una suficiente medida de fidelidad al derecho como disposición motivacional dominante. La consecuencia fundamental consiste en que la imputación jurídico-penal ha de ser modelada bajo la adopción de un principio de contra-facticidad de la imputación, con arreglo al cual aquélla admite ser reconstruida como un programa de racionalización negativa del comportamiento del autor ${ }^{79}$.

${ }^{78}$ Nótese que ello no implica validar la idea de que razones y motivos constituyan categorías diferentes. Antes bien, un motivo no es más que una razón que puede ser invocada como respuesta a la pregunta de por qué alguien hizo o dejó de hacer algo. Véase Norman, R., "Practical Reasons and the Redundancy of Motives", en: Ethical Theory and Moral Practice 4, 2001, págs. 3-22., p. 6 ss.

${ }^{79}$ En detalle Mañalich, J. P. "La exculpación..." op. cit., págs. 7 ss., 20 ss. 
Juan Pablo Mañalich R.

\section{5. La producción legislativa de razones obligantes}

Tal como ya se ha sugerido, esta concepción de la imputación jurídico-penal resulta anclada a una comprensión de las normas cuyo quebrantamiento puede resultar delictivo como razones externas para la acción, cuya validación jurídica les imprime, en la terminología favorecida por Hart, el carácter de razones perentorias e "independientes-del-contenido" para la acción ${ }^{80}$. Es precisamente esta última propiedad la que Duff entiende como incompatible con una justificación democrática de la autoridad del derecho (penal). Hart fundamenta tal caracterización de las reglas jurídicas capaces de exhibir fuerza obligante a través de un análisis de la noción de orden (command) a la que Bentham recurriera para intentar dar cuenta de la específica normatividad del derecho. Por "perentoriedad" de una orden habría que entender que la propiedad de ésta consiste en la pretensión de quien la emite de que su destinatario "suprima la deliberación" acerca de la realización o falta de realización de aquello a lo cual la orden se refiere ${ }^{81}$. Por "independencia-del-contenido", a su vez, habría que entender el hecho de que quien imparte la orden

may issue many different commands to the same or different people and the actions commanded may have nothing in common, yet in the case of all of them the commander intends his expression of intention to be taken as a reason for doing them. ${ }^{82}$

El interés de Hart por reconstruir el concepto de orden delineado por Bentham, empero, concierne a su conjetura de que esos dos aspectos no son privativos de las órdenes susceptibles de ser válidamente impartidas por alguien, sino que determinan el núcleo de un conjunto

${ }^{80}$ Hart, Essays... op. cit., págs. 243 ss., 255 ss.

${ }^{81}$ Ibídem, pág. $253 \mathrm{~s}$.

82 Ibídem, pág. 254. La primera formulación que Hart ofreciera de esta noción de razón "independiente-del-contenido" para caracterizar el fenómeno de la obligación jurídica se encuentra en Hart, H. L. A., "Legal and Moral Obligation", en: Melden, A. I., Essays in Moral Philosophy, Seattle y Londres: Washington University Press, 1958, págs. 82-107, pág. 100 ss. 
Responsabilidad, autoridad y democracia una exploración crítica ...

de fenómenos normativos cuyo común denominador radica en la generación de obligaciones a través de un ejercicio de autoridad práctica, esto es, de autoridad capaz de producir razones para la acción. E incluso allí donde los criterios de reconocimiento de semejante ejercicio de autoridad normativa no se encuentran propiamente institucionalizados, agrega Hart, en todo caso será posible identificar su ejercicio en referencia al rasgo definitorio de toda "autoridad práctica", a saber, el hecho de que las "expresiones de intención" de alguien, en lo concerniente al comportamiento de otros, "sean aceptadas como razones perentorias, e independientes del contenido, para la acción"83.

El paso argumentativo crucial que Hart propone, a este respecto, consiste en la observación de que es perfectamente posible desvincular la tematización de tal producción artificial de razones perentorias e independientes-del-contenido a través de un ejercicio de autoridad práctica, por un lado, de la especificidad del tipo de acto de habla consistente en la impartición de una orden, por otro. Pues sólo a través de tal desvinculación es posible ofrecer una explicación satisfactoria de la producción del derecho por vía de legislación, para lo cual es imprescindible dar cuenta de la importancia que en ello tiene la observancia de un determinado procedimiento, la satisfacción de cuyas condiciones pueda concluir en la generación "performativa" de nuevas razones para la acción ${ }^{84}$.

Esto vuelve reconocible cuán problemática resulta ser la contraposición misma de los conceptos de prohibición y declaración que Duff sugiere. A este respecto, es especialmente llamativo que Duff vincule la concepción hartiana de las reglas de obligación con el modelo de las "órdenes del soberano", en circunstancias de que, como se ha mostrado hasta aquí, Hart se dedicó con particular consistencia a desmantelar ese mismo modelo como esquema de reconstrucción de la legislación. Pues la caracterización hartiana de la producción legislativa de razones perentorias e independientes-del-contenido para la acción admite ser justamente reformulada en términos de que la

${ }^{83}$ Hart, Essays... op. cit., pág. 258.

${ }^{84}$ Ibídem, pág. $259 \mathrm{~s}$. 
Juan Pablo Mañalich R.

promulgación -en el sentido de "puesta en vigor"- de una norma jurídica de prohibición o de requerimiento, en cuanto razón jurídicamente obligante, se corresponde con la realización de un acto de habla declarativo, y no imperativo ${ }^{85}$.

Hart sugiere que en un estadio pre-institucional no es posible identificar una forma embrionaria de autoridad legislativa más que en referencia a una disposición socialmente generalizada a reaccionar hostilmente frente al quebrantamiento de determinados estándares de comportamiento, cuya fuerza obligante es reconocible en esa disposición informalmente represiva, que a su vez es expresiva de la adopción de actitudes normativas que imponen el correspondiente estatus normativo sobre el correspondiente tipo de acción ${ }^{86}$. Con la emergencia de un sistema jurídico propiamente diferenciado, el reconocimiento de la autoridad para la producción de reglas vinculantes deja de ser (al menos: directamente) dependiente de la adopción generalizada de actitudes normativas manifestadas en la disposición a responder con sanciones a su eventual quebrantamiento ${ }^{87}$. Pues lo que distingue a un sistema jurídico propiamente diferenciado es, ante todo, la institucionalización de criterios de reconocimiento de reglas primarias de obligación -así como de reglas secundarias de diversa índole- que exhiben validez jurídica en cuanto pertenecientes a un determinado sistema jurídico $^{88}$. La innovación que trae consigo semejante institucionalización de criterios de reconocimiento se deja describir con mayor precisión como sigue: el estatus normativo de la acción cuya omisión o ejecución es jurídicamente exigida es impuesto como resultado de un acto de habla formalizado, consistente en la promulgación (o puesta en vigencia) de una regla de obligación.

${ }^{85} \mathrm{Al}$ respecto Mañalich, J.P., "El concepto de..." op. cit., pág. $583 \mathrm{~s}$.

${ }^{86}$ Detalladamente Mañalich, J. P., "El concepto de..." op. cit., págs. 572 ss., 576 ss.

${ }^{87}$ Hart, Essays... op. cit., pág. $257 \mathrm{~s}$.

${ }^{88}$ Sobre la conexión conceptual entre la identidad de un sistema jurídico y los criterios de pertenencia de las reglas que lo integran, véase Raz, J., The Concept of a Legal System, 2a ed, Oxford: Clarendon Press, 1980. pág. 187 ss. 
Responsabilidad, autoridad y democracia una exploración crítica ...

En el vocabulario de la teoría de los actos de habla, la concepción de la legislación susceptible de ser atribuida a Hart se distingue por representar la puesta en vigencia de una regla jurídica como el resultado de un acto de habla que conjuga dos fuerzas ilocutivas diferentes. Esta conjunción, empero, no admite ser entendida como una simple combinación, sino más bien como una derivación de una fuerza ilocutiva a partir de la otra. En efecto, las reglas de obligación se distinguen por imponer un determinado estatus deóntico sobre un cierto tipo de acción. Tal imposición de un estatus se deja entender como el resultado de un acto de habla declarativo ${ }^{89}$, en la medida en que ese estatus cuente como un estatus funcional (o "estatus-función"), esto es, como un estatus cuya imposición sirve a la realización de una determinada función ${ }^{90}$, la cual consiste en proveer una razón para la omisión o la ejecución de la acción correspondiente. De ahí que a través del acto de habla declarativo por el cual se impone el correspondiente estatus normativo sobre el tipo de acción en cuestión, precisamente a través de su declaración como prohibido o requerido, se obtenga el resultado ilocutivo característico de un acto de habla directivo ${ }^{91}$. Y es exactamente esto lo que Hart tematiza cuando observa que la actividad legislativa puede ser entendida en términos de la producción "performativa" de "nuevas razones o guías para la acción"92.

${ }^{89}$ Searle, J., Expression and Meaning, Cambridge: Cambridge University Press, 1979, pág. 16 ss.

${ }^{90}$ Según Searle, lo distintivo de todo estatus funcional consiste, por un lado, en el hecho de que su imposición y conservación es dependiente de un ejercicio de intencionalidad colectiva, así como, por otro lado, en el hecho de que la entidad en cuestión exhiba el estatus respectivo no exclusivamente por su estructura intrínseca, sino en virtud de la imposición y el reconocimiento colectivo de ese estatus; véase Searle, J., Making the Social World, Oxford: Oxford University Press, 2010., pág. 58 ss.

${ }^{91}$ Véase, Searle, op. cit., pág. 28.

${ }^{92}$ Hart, Essays... op. cit., pág. 260. 
Juan Pablo Mañalich R.

\section{Democracia y autoridad práctica}

\section{IV.1. La independencia-del-contenido como marca de autoridad}

Según ya se estableciera, Duff impugna la idea de que, tratándose de delitos constitutivos de mala in se, la específica incorrección del comportamiento respectivamente delictivo pudiera quedar asociada al quebrantamiento de una regla que funcione como una razón independiente-del-contenido. Pues:

whatever content-independent reasons such prohibitions offered citizens to refrain from mala in se would be the wrong kind of reason. If the law is to address us as citizens (not as subjects), it must address us in terms of the values that supposedly structure our polity and that are expressed in its own provisions. It must address us honestly: the reasons it offers us for refraining from conduct it defines as criminal must at least in the first instance be the reasons that justify the demand that we refrain from it $[\ldots]^{93}$.

En otros términos, lo que Duff denuncia es la "radical falta de ajuste" que, de acuerdo con una concepción hartiana de la autoridad legislativa, habría que reconocer "entre las razones que el derecho ofrece a los ciudadanos para actuar como aquél demanda y las razones que supuestamente justifican el contenido de esas demandas", lo cual resultaría en una "falta de transparencia" en la manera en que el derecho se dirige a aquellos a quienes pretende vincular" ${ }^{94}$. Con esto llegamos efectivamente al núcleo del problema, puesto que una justificación propiamente democrática de la autoridad legislativa, capaz de producir razones artificiales para la acción, necesita asumir como virtuosa tal falta de transparencia entre esas mismas razones artificiales, por un lado, y el conjunto de razones (sustantivas) susceptibles de ser esgrimidas en su justificación, por otro. Y la manera en que el discurso jurídico se muestra ontológicamente comprometido, por

${ }^{93}$ Duff. A., Answering... op. cit., pág. 86.

${ }^{94}$ Duff, A., Punishment... op. cit., pág. 58. 
Responsabilidad, autoridad y democracia una exploración crítica ...

vía de hipóstasis, con la existencia de normas con fuerza obligante es expresiva de la (relativa) independencia que les reconocemos en su aplicación, como razones para la acción, frente a aquellas razones que eventualmente las justifican ${ }^{95}$.

Una muy importante contribución a la clarificación de este último problema ha sido provista por Sciaraffa, cuyo análisis del concepto de razón independiente-del-contenido arranca de la constatación de que los esfuerzos por esclarecer la propiedad designada por la expresión "independencia-del-contenido" han tendido a fallar al no tomarse nota de la inadecuación terminológica de esa misma expresión ${ }^{96}$. Así, y sobre la base de la célebre distinción entre los conceptos de "significado natural" y "significado no-natural", introducida por Grice ${ }^{97}$, Sciaraffa sostiene que la mejor reconstrucción de la caracterización hartiana de una razón para la acción como "independiente-del-contenido" consiste en su identificación con una intención de que alguien haga o no haga algo ${ }^{98}$. El carácter "no-natural", y en tal medida artificial, de semejantes razones explica que ellas se distingan por no exhibir una relación directa con las acciones para cuya ejecución u omisión ellas mismas cuentan como razones:

when one acts on the basis of a content-independent reason, one acts for the reason that some person intends for one to so act. [...] One's reason to act is not based on the reasons other than intentions that in the most basic case justify intentions to act. Rather, one's

${ }^{95}$ Raz, J., Practical Reason and Norms, 2a ed., Princeton: Princeton University Press, 1990, pág. 79 s. Para la distinción entre discursos de fundamentación y discursos de aplicación de normas,véase Günther, K., Der Sinn für Angemessenheit, Suhrkamp, Fráncfort del Meno, 1988, págs. 28 ss., 37 ss.

${ }^{96}$ Sciaraffa, S., "On Content-Independent Reasons: It's not in the Name", en: Law and Philosophy 28, 2009, págs. 233-260, pág. 233 ss.

${ }^{97}$ A cuyo trabajo Hart mismo hacía referencia en el contexto de su presentación de la noción de razones perentorias e independientes-del-contenido; véase Hart, Essays...op. cit., pág. 244, nota 2.

${ }^{98}$ Sciaraffa, op. cit, pág. 245 ss. 
Juan Pablo Mañalich R.

reason for acting is an intention that in turn is (in the most basic case) based on non-intention based reasons ${ }^{99}$.

Aquí es crucial reparar en dos aspectos del análisis ofrecido por Sciaraffa. En primer lugar, él tematiza explícitamente la posibilidad de que la intención en cuestión, que pueda fungir como fundante de una razón para que una acción -sea omitida o ejecutada, sea atribuible a algún "agente ficticio", o bien a alguna "persona corporativa", como lo sería, entre otros, una asamblea legislativa ${ }^{100}$. En este último caso, lo determinante es que la correspondiente razón independiente-del-contenido para la acción tendría que ser caracterizada como resultante del hecho de que el respectivo agente corporativo sea "representado como intentando" que $\phi$ sea ejecutada u omitida. Esto quiere decir, entonces, que el estatus del sujeto de la correspondiente intención qua agente artificial trae consigo la institucionalización de algún mecanismo que haga posible atribuirle la formación de esa intención. Un mecanismo de esa índole consiste, precisamente, en el procedimiento legislativo definido en la constitución de un Estado.

En segundo lugar, Sciaraffa observa que es imprescindible diferenciar el concepto de una razón para la creencia o para la acción, según corresponda, por un lado, del concepto de condición posibilitadora de la constitución de semejante razón, por otro ${ }^{101}$. Restringiendo el análisis a las razones independientes del contenido, un ejemplo de una condición posibilitadora para que la intención de $\mathrm{X}$, en cuanto a que $\mathrm{Y}$ se forme una creencia, se constituya como una razón para que Y se forme esa misma creencia consiste en la confiabilidad (comparativa) de X. Tal condición consiste en que Y pueda razonablemente esperar que $\mathrm{X}$ dispone de mejor información que $\mathrm{Y}$ en lo referido al objeto de la potencial creencia; en tal medida, se trata aquí de una condición posibilitadora de naturaleza epistémica, que favorece la efectividad de la intención expresada por X como razón para que $\mathrm{Y}$ se forme la

99 Ibídem, pág. $248 \mathrm{~s}$.

100 Ibídem, pág. 249.

${ }^{101}$ Ibídem, pág. 249 s. 
creencia correspondiente ${ }^{102}$. Desde este punto de vista, y por contraste, lo distintivo de una razón independiente-del-contenido para la acción es que a su respecto pueden venir en consideración condiciones posibilitadoras que no quedan reducidas a aquellas de naturaleza epistémica, pudiendo reconocerse, asimismo, condiciones posibilitadoras de naturaleza directamente práctica ${ }^{103}$. Este es precisamente el estatus de lo que identificamos como un reconocimiento de autoridad en sentido práctico: la intención de $\mathrm{X}$ en cuanto a que $\mathrm{Y}$ ejecute la acción $\phi$ podrá constituirse como razón para que $\mathrm{Y}$ ejecute $\phi$, en la medida en que Y reconozca autoridad a X. Y como observa Sciaraffa, semejante reconocimiento de autoridad práctica, en cuanto condición posibilitadora de la generación de razones independientes-del-contenido, puede resultar compatible con el ethos igualitarista que es definitorio del ideal democrático ${ }^{104}$.

Esto sienta las bases para una reinterpretación democrática de la manera en que, por vía legislativa, el Estado de una comunidad política puede llegar a producir razones para la acción que vinculen, qua razones perentorias, con "independencia del contenido": el carácter jurídicamente prohibido o requerido de un tipo de acción, impuesto sobre éste a través de la norma en cuestión, funciona como el indicador institucional de la intención de que sean omitidas o ejecutadas acciones que ejemplifican ese tipo de acción, en cuanto intención atribuible a un agente artificial al cual se reconoce, institucionalmente, autoridad práctica. En tal medida, la eficacia del respectivo mecanismo legislativo para la producción artificial de razones para la acción resulta ser (políticamente) contingente ${ }^{105}$.

102 Ibídem, pág. $250 \mathrm{~s}$.

${ }^{103}$ Sciaraffa, op. cit., pág. $251 \mathrm{~s}$.

${ }^{104}$ Sciaraffa, op. cit., pág. 252.

${ }^{105}$ Defendiendo la tesis de la contingencia de la producción jurídica de razones para la acción, véase en detalle Enoch, op. cit., págs. 16 ss., 26 ss. 
Juan Pablo Mañalich R.

\section{IV.2. El alcance de la perentoriedad y el problema del doble cómputo}

Como ha sostenido Christiano, la autoridad democrática de una asamblea legislativa necesita ser entendida como una autoridad práctica en el sentido recién precisado ${ }^{106}$, esto es, como una autoridad a través de cuyo ejercicio puedan ser producidas razones perentorias e independientes-del-contenido para la acción, y en tal medida vinculantes para quienes están sometidos al ejercicio de esa misma autoridad ${ }^{107}$. Más precisamente, las razones para la acción producidas por una asamblea legislativa, dotada de autoridad democrática, deben ser entendidas como independientes-del-contenido, en la medida en que ellas son el resultado de una decisión, que en cuanto tal plasma la formación de una intención ${ }^{108}$, la cual pretende vincular a todos quienes resultan sometidos al poder de decisión así ejercido. Y tales razones para la acción deben ser entendidas, asimismo, como perentorias (pre-emptive), puesto que el reconocimiento de la autoridad a través de cuyo ejercicio ellas son producidas supone reconocer que ellas han de operar reemplazando y -en tal medida- excluyendo las razones inmediatamente pertinentes en la situación en la cual el agente se encuentra.

Nótese, ahora bien, que el conjunto de razones situacionalmente pertinentes, susceptibles de verse excluidas en razón de la perentoriedad predicable de la respectiva regla obligante, en cuanto autoritativamente legitimada, no será necesariamente idéntico al conjunto de razones que, fundamentando la decisión adoptada por el agente legislativo, se ven reflejadas, qua razones subyacentes, en la razón perentoria artificialmente producida ${ }^{109}$. Y que precisamente tales razones subyacentes hayan de resultar excluidas en virtud del carácter

${ }^{106}$ Christiano, T., "The Authority of Democracy". The Journal of Political Philosophy 12, n. ${ }^{\circ} 3,2004$, págs. 266 ss., 284 ss.

107 Ibídem, pág. 287.

${ }^{108}$ Véase Raz, J., Practical... op. cit., pág. 65: "To decide is to form an intention".

${ }^{109}$ Véase Raz (1986), pág. 41 s.; al respecto, Navarro y Redondo (1994), págs. 47 s., 53 s., quienes objetan a Raz confundir las razones subyacentes con las razones independientes efectivamente aplicables en la situación. 
Responsabilidad, autoridad y democracia una exploración crítica ...

perentorio de la razón para la acción en la cual ellas se ven reflejadas es lo que Duff denuncia bajo la acusación de la ya mencionada "falta de transparencia". Así contextualizada, la objeción de Duff concierne al problema del así llamado "alcance de la exclusión", consistente en el aparente dilema al que conduciría la caracterización de las reglas jurídicas de obligación como razones perentorias. Para estos efectos, puede ser conveniente asumir que la caracterización de una razón para la acción como perentoria, à la Hart, resulta equivalente a su caracterización como "protegida", à la $\mathrm{Raz}^{110}$, esto es, como

a systematic combination of a reason to perform the act one has undertaken to perform, or the one required by the rule, and an exclusionary reason not to act for certain reasons (for or against the act $)^{111}$.

Con ello, el problema del alcance de la exclusión se deja formular a través de la siguiente pregunta: ¿se extiende el efecto excluyente que convierte a una razón en una razón protegida a aquellas razones subyacentes que, en cuanto razones "dependientes" 112 , se ven reflejadas en la razón protegida en su dimensión de razón de primer orden? ${ }^{113}$.

Essert sostiene que cualquiera de las dos respuestas posibles -la afirmativa y la negativa- a esa pregunta resulta insostenible en atención a las premisas de la concepción de Raz. Pues si se afirma que las razones subyacentes resultarían excluidas, la concepción raziana de la autoridad como servicio, en cuanto construida a partir de la así

${ }^{110}$ Véase Raz (1979), pág. 17 s. Nótese que Raz mismo llega a presentar su concepción general de la autoridad práctica como integrando la "tesis de la perentoriedad" (pre-emption thesis); véase Raz (1995), págs. 211 ss., 214.

${ }^{111}$ Raz (1990), pág. 191.

112 Nótese que Raz valida un uso ambiguo de la expresión "razón dependiente", en términos tales que ésta pueda designar, según cuál sea el contexto, o bien la razón protegida que refleja el respectivo conjunto de razones subyacentes, o bien cualquiera de las razones subyacentes que se ven reflejadas en aquélla; véase Raz (1986), pág. 41.

${ }^{113}$ Essert (2012), págs. 49 ss., 59 ss. 
Juan Pablo Mañalich R.

llamada "tesis de la dependencia"114, se ve comprometida; y de afirmarse, por el contrario, que las razones dependientes no resultarían excluidas, el problema pasa a ser el del "doble cómputo" ${ }^{115}$ : si la respectiva razón protegida, en cuanto razón de primer orden, habla a favor de la ejecución de la acción $\varphi$, entonces el agente contaría no sólo con esta razón para ejecutar $\varphi$, sino asimismo con el conjunto de las razones dependientes que se ven reflejadas en aquélla, lo cual arrojaría una imagen distorsionada de la deliberación práctica susceptible de ser desplegada por el agente.

La solución favorecida por Essert consiste en renunciar a la noción misma de razón protegida, descartando así que una misma razón, caracterizada como excluyente de razones contrarias a la ejecución de la acción $\varphi$, pueda asimismo funcionar como una razón de primer orden para la ejecución de $\varphi^{116}$. Con ello, las únicas razones a favor de la ejecución de $\varphi$ serían, en tal caso, las razones dependientes que sustentan la correspondiente razón excluyente. Esto hace posible sortear el problema del doble cómputo, pero a un precio para nada despreciable. Pues renunciar a la caracterización de las reglas jurídicas de obligación como razones protegidas es renunciar a la idea de que el derecho pueda producir razones para la acción, lo cual compromete la noción misma de una auténtica "autoridad del derecho", entendida en el sentido de una autoridad práctica. Y no está de más apuntar que la solución sugerida por Essert se acerca llamativamente a la manera en que Duff da cuenta de las implicaciones normativas de la declaración legislativa que criminaliza un delito constitutivo de malum in se:

In the case of mala in se, what the law defining them as offences declares or reminds us of is not just that we have categorical reason to refrain from the specified conduct, but that that reason serves to exclude the conduct from normal considerations as an option ${ }^{117}$.

${ }^{114}$ Raz (1986), págs. 38 ss., 42 ss.

${ }^{115}$ Essert (2012), págs. 59 s., 66 ss.; véase también Navarro y Redondo (1994), pág. $47 \mathrm{~s}$.

${ }^{116}$ Essert (2012), pág. 73 ss.

${ }^{117}$ Duff (2007), pág. 222. 
Responsabilidad, autoridad y democracia una exploración crítica ...

Más allá de que, a diferencia de Essert, Duff insista en que semejante declaración tendría una función eminentemente recordativa del efecto excluyente de la respectiva razón categórica, qua "razón moral", para la omisión de una acción cuya ejecución es (declarada) criminal, es claro que semejante recordatorio tendría que ser entendido como un servicio prestado por la correspondiente asamblea legislativa, en cuanto detentadora de autoridad para criminalizar. El problema está, sin embargo, en que la concepción de la autoridad como servicio, sustentada en la tesis de la "justificación normal", resulta enteramente insensible a la especificidad de una justificación democrática de la autoridad legislativa. De acuerdo con Raz, la tesis de la justificación normal consiste en que

the normal way to establish that a person has authority over another person involves showing that the alleged subject is likely better to comply with reasons which apply to him (other than the alleged authoritative directives) if he accepts the directives of the alleged authority as authoritatively binding and tries to follow them, rather than by trying to follow the reasons which apply to him directly ${ }^{118}$.

Esto quiere decir que el reconocimiento de autoridad práctica a $\mathrm{X}$, por parte de $\mathrm{Y}$, tendría que ser funcional a la puesta en marcha de una "estrategia indirecta" para optimizar la adecuación del resultado de la deliberación de $\mathrm{Y}$ a las razones inmediatamente pertinentes en la situación en la que Y se encuentra, en la medida en que la directiva suministrada por $\mathrm{X}$ refleje adecuadamente el balance resultante de la consideración de esas mismas razones, descargando a Y de la necesidad de efectuar ese balance por sí y aligerando, en esa misma medida, la deliberación de $\mathrm{Y}^{119}$. Justamente en este aligeramiento de la deliberación práctica de agentes, funcional a la optimización de la adecuación de su comportamiento a razones de cuyo seguimiento

${ }^{118} \operatorname{Raz}$ (1986), pág. 53 (cursivas suprimidas); véase también Raz (1995), pág. 214.

119 Véase Raz, J., The Morality of Freedom, Oxford: Clarendon Press, , 1986, pág. $51 \mathrm{~s}$. 
Juan Pablo Mañalich R.

directamente quedan descargados, consistiría el servicio prestado por quien ejerce autoridad práctica a su respecto.

Semejante concepción instrumentalista de la autoridad práctica se distingue por ignorar la significación política del desacuerdo potencialmente existente, entre los ciudadanos de una democracia, en cuanto a cómo ha de organizarse su propia comunidad política ${ }^{120}$. Políticamente, tal desacuerdo es constitutivo del sentido que adquiere la decisión concerniente al estatus normativo de tal o cual tipo de acción, en cuanto decisión democráticamente legitimada, lo cual significa: en cuanto decisión legitimada por la manera en que su adopción representa el resultado obtenido a través de un procedimiento que imprime carácter vinculante a su resultado, por el hecho de que ese procedimiento asegura el resguardo de la posibilidad, reconocida por igual a cada ciudadano, de tomar parte en la deliberación conducente a la decisión que zanja autoritativamente el conflicto concerniente al estatus normativo del respectivo tipo de acción. Así, la producción legislativa de normas consistentes en reglas de obligación puede adquirir legitimidad democrática en la medida en que el procedimiento legislativo satisfaga el requerimiento de publicidad que es definitorio del ideal democrático.

Democráticamente, la justicia del resultado del proceso legislativo tiene que consistir en la satisfacción de lo que Christiano denomina el "principio de la realización pública de una igual promoción de intereses"121. Este principio especifica una noción de justicia social concerniente a la clase de demandas que las personas pueden dirigirse, unas a otras, en la determinación del equilibrio de bienestar que ha de resultar de la promoción igualitaria de los intereses de bienestar de cada cual. Puesto que, así entendida, la justicia de los arreglos alcanzados

${ }^{120}$ Así Christiano op. cit., pág. 279 s., aun cuando cualificando la significación de tal desacuerdo como "moral", y no como "política". La sustitución aquí favorecida se funda en que, como ha observado Atria, el lenguaje de lo político determina que "en la deliberación política no hay[a] espacio para distinguir lo político de lo moral"; véase Atria, F., La forma del derecho, Madrid, Barcelona, Buenos Aires y San Pablo: Marcial Pons, 2016, pág. $380 \mathrm{s.}$ 
Responsabilidad, autoridad y democracia una exploración crítica ...

es una función de demandas (claims) susceptibles de ser esgrimidas entre personas, aquélla debe ser entendida en la forma de un "principio débilmente público":

The weak notion of publicity demands that the principles of justice be ones that people can in principle see to be in effect or not. [...] To be sure, publicity does not require that each person actually see that he or she is being treated justly. It requires only that each person can see that he or she is being treated justly given a reasonable effort on his part ${ }^{122}$.

Si se satisfacen las condiciones de las cuales depende que la producción legislativa de una regla jurídica de obligación imprima a ésta la marca de la resolución públicamente justa de un desacuerdo concerniente al estatus normativo del tipo de acción sometido a la regla, en el sentido de que el proceso resultante en su puesta en vigor ha honrado la posibilidad de igual participación pública en la correspondiente toma de decisión, entonces cabe asumir que esa regla justificadamente exhibirá la pretensión de vincular a todos aquellos a quienes se reconoce dicha posibilidad de igual participación, con independencia de su eventual falta de adhesión sustantiva a la regla así producida. En una terminología alternativa, cabría decir que la pretensión política de obligatoriedad de una regla democráticamente instituida descansa en el ejercicio de autonomía pública que cada ciudadano puede desplegar en el proceso de su producción, quedando vinculado por ésta en el ejercicio de su autonomía privada ${ }^{123}$.

El hecho de que las normas democráticamente legitimadas pretendan vincular también a aquellos que sustantivamente rechazan su puesta en vigor o demandan su derogación habla decisivamente a favor de resolver el ya mencionado problema del "doble cómputo"

${ }^{122}$ Christiano, op. cit., pág. 270.

${ }^{123}$ Véase Günther, K., Schuld und kommunikative Freiheit, Fráncfort del Meno: Suhrkamp, 2005, págs. 245 ss., 248 ss.; Kindhäuser, U. y Mañalich, J. P., Pena y culpabilidad en el Estado democrático de derecho, 2a ed., Montevideo y Buenos Aires: BdF, 2011, págs. 68 ss., 93 ss., 114 ss. 
Juan Pablo Mañalich R.

tomando al pie de la letra su caracterización como reglas que funcionan como razones perentorias para la acción. Su perentoriedad consiste precisamente en su fuerza excluyente de las razones que pudieran reclamar pertinencia situacional ${ }^{124}$, incluidas aquellas razones que pueden verse reflejadas en la regla autoritativamente instituida. Pues justamente en esto consiste que la pretensión de vinculación pública exhibida por la norma no dependa de las razones sustantivas que la fundamentan, sino de su estatus como resultado de un proceso de deliberación democráticamente organizado, que políticamente también obliga a quien, por el momento, queda en la vereda de la minoría. En tal medida, una norma de comportamiento democráticamente legitimada puede funcionar como una razón perentoria para la acción precisamente porque ella vincula con "independencia-del-contenido".

\section{IV.3. La democracia como procedimiento}

Aquí no está de más reparar en que, en su defensa de una concepción democrática de la autoridad legislativa qua autoridad práctica, Christiano observa que el tipo de legitimidad así tematizado no puede coincidir con aquella forma de legitimidad, "altamente inusual", bajo la cual "cada cual puede ver que la sustancia de la legislación es justa", pues ésta no es una situación que "surja en los modernos estados democráticos"125. Esto sugiere que la concepción de la autoridad del derecho penal que Duff hace suya parecería hallarse anclada a un paradigma pre-moderno de legitimación jurídica ${ }^{126}$. Pues la apelación a "los valores que supuestamente estructuran nuestra comunidad política" para calibrar la voz en la cual el derecho penal de esa misma comunidad ha de hablarnos como ciudadanos, y no como súbditos $^{127}$, resulta del todo insensible a la significación constitutiva que la

${ }^{124}$ Christiano, op. cit., pág. 287.

${ }^{125}$ Christiano, op. cit., pág. 285.

${ }^{126}$ Para una caracterización del "derecho premoderno", que justamente enfatiza su desconocimiento del carácter (políticamente) artificial de la normatividad jurídica, véase Atria, op. cit., pág. 56 ss.

${ }^{127}$ Duff, A., Answering... op. cit., pág. 86. 
Responsabilidad, autoridad y democracia una exploración crítica ...

posibilidad del desacuerdo sustantivo acerca de las pautas elementales de comportamiento que han de vincular a los ciudadanos de una democracia adquiere para la articulación de la propia práctica política de tal democracia.

Esto contribuye a explicar el rechazo del "procedimentalismo político" que Duff asocia a su defensa de la presunta irrelevancia normativa de las reglas que especifican las formas de comportamiento constitutivas de mala in se. De acuerdo con una concepción procedimentalista, cabría decir que la autoridad de las normas de comportamiento jurídico-penalmente reforzadas deriva "no de su contenido, sino de los procedimientos a través de los cuales ellas son creadas". Ante esto, Duff sostiene lo siguiente:

We cannot, however, plausibly ground the authority of central parts of the criminal law in this way. For if we are to agree on procedures to structure the polity, we must be able to count on some level of mutual respect between those who are to agree on and work within the procedures; that is one way in which even proceduralists must appeal to agreement on substantive values. But it is hard to imagine a respect that is robust enough to underpin the requisite procedures which would not also preclude murdering, raping or subjecting to other central mala in se those whom I respect ${ }^{128}$.

Duff sugiere, en otras palabras, que una adhesión individual al procedimiento legislativo que una comunidad política se da a sí presupondría una adhesión individual a estándares de comportamiento inmediatamente fundados en valores sin cuya aceptación sería inconcebible aquella adhesión al procedimiento legislativo. Esta sugerencia deviene difícilmente sostenible, empero, si el problema se examina, por ejemplo, desde el punto de vista de la ética del discurso habermasiana, que representa uno de los intentos filosóficamente más célebres de sustentación de una fundamentación procedimentalista de normas democráticamente legitimadas. Y esto interesa no porque venga al

${ }^{128}$ Duff, A., Answering... op. cit., pág. 87. 
Juan Pablo Mañalich R.

caso defender el proyecto filosófico-jurídico de Habermas, que ciertamente exhibe flancos muy difíciles de cerrar ${ }^{129}$, sino para dar cuenta de lo indebidamente simplista que resulta ser el ataque que Duff dirige a las posiciones procedimentalistas.

Habermas entiende que el "principio de la democracia" se constituye como la especificación del así llamado "principio del discurso", en cuanto premisa abstracta para la fundamentación de "normas de acción", tratándose de normas que llegan a exhibir "forma jurídica"; en tal medida, el principio de la democracia es a la fundamentación de normas capaces de exhibir validez jurídica lo que el principio de universalización es a la fundamentación de normas capaces de reclamar validez moral ${ }^{130}$. En el nivel de abstracción que le es propio, y que sería por consiguiente neutral frente a la distinción entre validez moral y validez jurídica, el principio del discurso estatuye que son válidas "precisamente aquellas normas de acción a las cuales todos los posiblemente afectados podrían dar su asentimiento como participantes en discursos racionales" 131 .

La especificación del principio del discurso resultante en la implementación del principio de la democracia pasa por la institucionalización de un procedimiento a través del cual una determinada comunidad política pueda darse reglas "que valen como expresión de una auto-comprensión colectiva consciente"132. Tal institucionalización asumiría la forma del establecimiento de "un sistema de derechos, que asegura a cada cual una igual participación en [un] proceso de producción del derecho que a la vez está garantizado en sus presupuestos

${ }^{129}$ Véase por ejemplo Christodoulidis, E., Law and Reflexive Politics. Dordrecht, Kluer, Boston y Londres, 1998, págs. 19 ss., 26 ss., para una crítica de la tesis habermasiana de la "interpenetración" entre principio del discurso y forma jurídica.

${ }^{130}$ Habermas, J., Faktizität und Geltung, Fráncfort del Meno, Suhrkamp, 1994, págs. 135 ss., 139 ss. Al respecto, y recientemente, De la Vega, O., Transparenz und Undurchsichtigkeit, 2016. Tesis doctoral disponible en: http://hss.ulb.unibonn.de/2016/4562/4562.pdf., págs. 47 ss., 65 ss.

${ }^{131}$ Habermas, J., op. cit., pág. 138.

132 Ibidem, pág. 139. 
Responsabilidad, autoridad y democracia una exploración crítica ...

comunicativos"133. En contra de lo sugerido por Duff, empero, Habermas entiende que de la fundamentación misma del principio del discurso, así como de las reglas de argumentación con pertinencia para el respectivo ámbito de problemas prácticos en el cual aquél pueda resultar aplicable a través de la correspondiente especificación, no es posible extraer la fundamentación de norma de comportamiento alguna. Pues los argumentos susceptibles de ser esgrimidos para convencer al potencial escéptico de la necesidad racional de aceptar el principio del discurso serían argumentos que se le dirigen en su estatus de participante en la argumentación, y no en su estatus de potencial agente situacionalmente enfrentado a alguna oportunidad para la acción ${ }^{134}$. De ahí que no sea factible una inferencia directa de normas de comportamiento a partir de la mera identificación reflexiva de los presupuestos pragmáticos de la argumentación susceptible de ser desplegada en pos de la fundamentación de alguna norma cualquiera, con independencia del contenido de esta.

A este respecto, es especialmente importante que Habermas observe que "en sociedades complejas, la moral adquiere efectividad, más allá del ámbito íntimo, recién por la vía de que ella sea traducida en el código del derecho" ${ }^{135}$. Pues esto sugiere que la apelación inmediata a valores morales comunitariamente compartidos no basta para identificar pautas de comportamiento correcto que puedan exhibir la fuerza normativa necesaria para vincular a los miembros de una comunidad política cuya forma de vida organizada haya de ser compatible con las circunstancias de una sociedad compleja. Ello hace posible entender, además, por qué la legitimación de normas jurídicas instituidas a través de un procedimiento legislativo que vuelve operativo el principio de la democracia necesariamente ha de mostrar un carácter holista: las

133 Ibidem, pág. 142.

134 Habermas, J., Moralbewußtsein und kommunikatives Handeln, Fráncfort del Meno: Suhrkamp, 1983, pág. 96.

135 Habermas, J., Faktizität, pág. 141. Una defensa especialmente lúcida de la tesis de la dependencia de la moral respecto del derecho se encuentra en Honoré, T., "The Dependence of Morality on Law". Oxford Journal of Legal Studies 13, 1993, passim. 
Juan Pablo Mañalich R.

normas democráticamente legitimadas resultan conjunta y sistémicamente legitimadas, en virtud de su modo de producción, sin que tenga sentido problematizar la validez, sub specie autoridad democrática, de alguna de esas normas considerada aisladamente ${ }^{136}$.

Lo anterior resulta de la mayor importancia en la evaluación de la caracterización que Duff hace de la autoridad propia de un derecho penal democrático, la cual, como ya se ha mostrado, está fuertemente condicionada por la distinción entre delitos constitutivos de mala in se y de mala prohibita. Pues al menos en la forma en que Duff la adopta, esta distinción es incompatible con la comprensión de la legitimación democrática de normas como una legitimación holista. Las normas de comportamiento jurídico-penalmente reforzadas son normas cuyo criterio de reconocimiento institucional queda normalmente constituido por la puesta en vigor de normas de sanción penal, las cuales especifican condiciones de punibilidad referidas a la realización de formas de comportamiento cuya ilicitud se identifica con el quebrantamiento de tales normas de comportamiento. Desde el punto de vista de la producción legislativa de las normas de sanción que en tal medida hacen identificables las correspondientes normas de comportamiento, no es posible distinguir entre delitos constitutivos de mala in se y delitos constitutivos de mala prohibita. Sorprendentemente, esto es algo que Duff mismo, aun cuando aparentemente sin advertirlo, llega a aceptar.

\section{IV.4. Malum in se como malum prohibitum}

En su esfuerzo por redefinir la distinción entre mala in se y mala prohibita, para darle así una base de plausibilidad más robusta, Duff observa que

we would do better to define mala prohibita as offences consisting in conduct that is not wrongful prior to the legal regulation that prohibits it, whilst mala in se are (supposedly) wrongs prior to any such legal regulation ${ }^{137}$.

${ }^{136}$ Véase Christiano, op. cit., pág. 268.

${ }^{137}$ Duff, A., Answering... op. cit., pág. 90. 
Responsabilidad, autoridad y democracia una exploración crítica ...

Lo crucial aquí es indagar en la razón que lleva a Duff a cualificar la afirmación de que la incorrección de un comportamiento constitutivo de malum in se sería "anterior" a -esto es, independiente de- la correspondiente regulación jurídica, a través del uso del adverbio "supuestamente". Duff ofrece la explicación en una nota al pie de página, en la cual sostiene que, "como asunto clasificatorio, un delito cuenta como un malum in se si se encuentra criminalizado porque se piensa que es incorrecto pre-jurídicamente"138. La clave, a este respecto, está dada por la cláusula "porque se piensa que". Pues esto muestra que, clasificatoriamente, lo que convertiría a un delito en una instancia de mala in se es dependiente de la manera en que se fundamenta su criminalización por parte de quien decide acerca de su criminalización. Si quien adopta la correspondiente decisión de criminalización es, verbigracia, una asamblea legislativa, ello significa que el estatus de malum in se del delito en cuestión justamente no será independiente del ejercicio de autoridad a través del cual la respectiva forma de comportamiento resulta criminalizada. Y si bien seguirá siendo posible, en tal caso, sostener que tal delito no constituye una instancia "genuina" de mala in se $e^{139}$, ello no será sino expresivo de que quien sostiene esto último simplemente manifiesta su falta de adhesión sustantiva a las "razones dependientes" susceptibles de ser esgrimidas para sustentar tal decisión de criminalización.

Semejante relativización de la distinción entre mala in se y mala prohibita es explícitamente asumida por Duff en su caracterización de lo que él mismo denomina "delitos híbridos", y que serían constitutivos de mala prohibita impuros ${ }^{140}$. Se trataría aquí, en efecto, de delitos cuya regulación legal especifica "reglas que imperfectamente capturan estándares que definen genuinos mala in se, la perpetración de los cuales, por consiguiente, frecuentemente mas no siempre involucrará la perpetración del malum in se relevante" ${ }^{141}$. Pero es todavía más importante advertir que, en relación con el subconjunto nuclear de los

${ }^{138}$ Ibídem, pág. 90, nota 40.

${ }^{139} \mathrm{Ibídem}$, pág. 169.

${ }^{140}$ Ibidem, págs. 90, 166 ss., 172.

${ }^{141}$ Duff, A., Answering... op. cit, pág. 169. 
Juan Pablo Mañalich R.

delitos constitutivos de "genuinos" mala in se, Duff también llega a admitir que su regulación puede adquirir auténtica fuerza normativa, precisamente en atención al factum de la irreductible posibilidad de desacuerdo en lo tocante al mérito de su respectiva criminalización:

In relation to mala in se, the law will sometimes have to provide precise determinationes [sic] of values whose precise legal meanings or implications are uncertain or controversial. The law defines just what counts as murder or theft or rape, as well as what counts as a justification for what would otherwise be a criminal action. In doing so, it specifies more determinate legal meanings for normative concepts whose prelegal meanings are typically less determinate, and it takes an authoritative stand on issues that may be controversial in the political community, such as the permissibility of euthanasia ${ }^{142}$.

Así, Duff se muestra dispuesto a reconocer la pretensión de auténtica autoridad normativa que reclama la regulación jurídica que especifica las condiciones de punibilidad de los delitos que contarían como mala in se, en la medida en que esa misma regulación reclama vincular a quienes no aceptan la base sustantiva de su pretensión de validez. Y es imposible soslayar la implicación que ello tiene, tal como Duff mismo lo hace explícito:

In such instances, what the law says to those who dissent from the stand it takes is not simply and unqualifiedly that the conduct in question is wrong, but rather that is now the community's authoritative view. Even if they dissent from its content, they have an obligation as members of the community to accept its authority -to obey the law, even if they are not persuaded by its content, unless and until they can secure a change in it through the normal political process ${ }^{143}$.

Esto es indicativo de que Duff llega a entender, incidentalmente, que no es posible dar cuenta de la aplicación de un régimen de

142 Duff, A., Punishment... op. cit., pág. 64.

143 Ibídem, pág. 65. 
derecho penal sin tomar nota de la pretensión de obligatoriedad de las normas jurídico-penalmente reforzadas, la cual se sustenta en una pretensión de autoridad que, de ser exitosamente desplegada, habría de producir una vinculación generalizada a esas mismas normas, con independencia del contenido de estas. Que Duff no convierta este hallazgo en una premisa para revisar su caracterización general de la "autoridad del derecho penal" y abandonar así la distinción entre mala in se y mala prohibita, entendida como una distinción ontológica, conspira seriamente contra la eficacia de su esfuerzo por vincular la imagen idealizada de un sistema de derecho penal a la reconducción de toda posible autoridad política al proyecto de la democracia. En tal medida, el defecto fundamental del programa de filosofía jurídico-penal de Duff no se encuentra en el "duro rechazo al comunitarismo" que Gargarella cree poder atribuirle ${ }^{144}$, sino más bien en una validación de premisas comunitaristas que socava el desarrollo consistente de una concepción estrictamente democrática de la autoridad del derecho.

\section{Bibliografía}

Atria, F., La forma del derecho, Madrid, Barcelona, Buenos Aires y San Pablo: Marcial Pons, 2016

Chehtman, A., Fundamentación filosófica de la justicia penal extraterritorial, Madrid, Barcelona, Buenos Aires y San Pablo: Marcial Pons, 2013.

Christiano, T., "The Authority of Democracy". The Journal of Political Philosophy 12, n. ${ }^{\circ} 3,2004$, págs. 266-290.

Christodoulidis, E., Law and Reflexive Politics. Dordrecht-BostonLondres: Kluwer Academic Publisher, 1998

Cruft, R.; Kramer, M. y Reiff, M., Crime, Punishment and Responsibility. The Jurisprudence of Antony Duff. Oxford: Oxford University Press, 2011.

De la Vega, O., Transparenz und Undurchsichtigkeit, 2016. Tesis doctoral disponible en: http://hss.ulb.unibonn.de/2016/4562/4562.pdf. 
Juan Pablo Mañalich R.

Duarte, L., Allowing for Exceptions: A Theory of Defences and Defeasibility in Law, Oxford: Oxford University Press, 2015.

Duff, A., Trials and Punishments, Cambridge: Cambridge University Press, 1986.

Duff. A., Philosophy and the Criminal Law. Principle and Critique. Cambridge: Cambridge University Press, 1998.

Duff, A., "Law, Language and Community: Some Preconditions of Criminal Liability", Oxford Journal of Legal Studies 18, 1998, págs. 189-206.

Duff, A., Punishment, Communication, and Community, Oxford y Nueva York: Oxford University Press, 2001.

Duff. A., Answering for Crime. Oxford y Portland (Or.): Hart Publishing, 2007.

Duff, A., "Authority and Responsibility in International Criminal Law", en: Besson, S. y Tasioulas, J., The Philosophy of International Law, Oxford y Nueva York: Oxford University Press, 2010, págs. 589-604.

Duff, A., "Responsibility, Citizenship, and the Criminal Law", en: Duff, A. y Green, S., 2011, págs. 125-148.

Duff, A., Sobre el castigo. Por una justicia penal que hable el lenguaje de la comunidad, Buenos Aires: Siglo XXI, 2015.

Duff, A.; Farmer, L.; Marshall, S. y Tadros, V., The Trial on Trial, vol. 1: Truth and Due Process, Oxford: Hart Publishing, 2004.

Duff, A.; Farmer, L.; Marshall, S. y Tadros, V., The Trial on Trial, vol. 2: Judgment and Calling to Account, Oxford: Hart Publishing, 2006. Duff, A.; Farmer, L.; Marshall, S. y Tadros, V, The Trial on Trial, vol. 3: Towards an Normative Theory of the Criminal Trial, Oxford: Hart Publishing, 2007.

Duff, A. y Green, S., Philosophical Foundations of Criminal Law. Oxford: Oxford University Press, 2011.

Enoch, D., "Reasong-Giving and the Law", en: Green, L. y Leiter, B., Oxford Studies in Philosophy of Law, vol. 1. Oxford y Nueva York: Oxford University Press, 2011, págs. 1-38.

Essert, C., "A Dilemma for Protected Reasons". Law and Philosophy, 31, 2012, págs. 49-75. 
Responsabilidad, autoridad y democracia una exploración crítica ...

Gardner, J., "Relations of Responsibility", en: Cruft, R.; Kramer, M. y Reiff, M., 2011, págs. 87-102.

Gargarella, R., Castigar al prójimo, Buenos Aires: Siglo XXI, 2016.

Godfrey-Smith, P., "Folk Psychology as a Model", Philosopher's Imprint 5, n. ${ }^{\circ}$ 6, 2005 disponible en: www.philosophersimprint. org $/ 005006 /$.

Günther, K., Der Sinn für Angemessenheit, Fráncfort del Meno: Suhrkamp, 1988.

Günther, K., Schuld und kommunikative Freiheit, Fráncfort del Meno: Suhrkamp, 2005

Habermas, J., Moralbewußtsein und kommunikatives Handeln, Fráncfort del Meno: Suhrkamp, 1983.

Habermas, J., Faktizität und Geltung, Fráncfort del Meno: Suhrkamp, 1994.

Harel, A., "The Triadic Relational Structure of Reponsibility: A Defence", en: Cruft, R.; Kramer, M. y Reiff, M., 2011, págs. 103-121.

Hart, H. L. A., Legal and Moral Obligation", en: Melden, A. I., Essays in Moral Philosophy, Seattle y Londres: Washington University Press, 1958, págs. 82-107.

Hart, H. L. A., Punishment and Responsibility, Oxford y Nueva York: Oxford University Press, 1968.

Hart, H. L. A., Essays on Bentham, Oxford: Clarendon Press, 1982.

Hohfeld, W., Fundamental Legal Conceptions, New Haven y Londres: Yale University Press, 1919.

Honoré, T., "The Dependence of Morality on Law". Oxford Journal of Legal Studies 13, 1993, págs. 1-17.

Kindhäuser, U. y Mañalich, J. P., Pena y culpabilidad en el Estado democrático de derecho, $2 \mathrm{a}$ ed., Montevideo y Buenos Aires: BdF, 2011.

Mañalich, J. P., Terror, pena y amnistía, Santiago: Flandes Indiano, 2010.

Mañalich, J.P., "Pena y ciudadanía”, en: Kindhäuser, U. y Mañalich, J.P., 2011, págs. 116-146.

Mañalich, J. P., "El concepto de acción y el lenguaje de la imputación”. DOXA 35, 2012, págs. 663-690. 
Juan Pablo Mañalich R.

Mañalich, J. P., "Reglas primarias de obligación. Las 'reglas del derecho penal', en: El Concepto de Derecho de H. L. A. Hart". Zeitschrift für Internationale Strafrechtsdogmatik 1/12, 2012, disponible en: http://www.zisonline.com/dat/artikel/2012_11_716.pdf.

Mañalich, J. P., "La exculpación como categoría del razonamiento práctico". InDret 1/2013, 2013, disponible en: http://www.indret. com/pdf/944.pdf.

Mañalich, J. P., "Normas permisivas y deberes de tolerancia". Revista Chilena de Derecho 41, 2014, págs. 473-522.

Mañalich, J. P., Norma, causalidad y acción, Madrid, Barcelona, Buenos Aires y San Pablo: Marcial Pons, 2014

Mañalich, J. P. "Duff, A., Sobre el castigo, México: Siglo XXI, 2015". Derecho y Crítica Social 2 (2): 265-274, 2016.

Matravers, M., "Duff on Hard Treatment", en: Cruft, R.; Kramer, M. y Reiff, M., 2011, pp. 68-83.

Moore, M., Placing Blame, Oxford y Nueva York: Oxford University Press, 1997.

Navarro, P., "Hechos y normas aplicables. Comentarios en torno a una propuesta de Ricardo Caracciolo", Isonomía 40, 2014, págs. 147-159.

Navarro, P. y Redondo, C., Normas y actitudes normativas, México: Fontamara, 1994.

Norman, R., "Practical Reasons and the Redundancy of Motives", Ethical Theory and Moral Practice 4, 2001, págs. 3-22.

Parfit, D., On What Matters, vol. I., Oxford y Nueva York: Oxford University Press, 2011.

Raz, J., The Authority of Law., Oxford: Oxford University Press, 1979.

Raz, J., The Concept of a Legal System, 2a ed., Oxford: Clarendon Press, 1980.

Raz, J., The Morality of Freedom, Oxford: Clarendon Press, 1986.

Raz, J., Practical Reason and Norms, 2a ed., Princeton: Princeton University Press, 1990

Raz, J., Ethics in the Public Domain, ed. rev., Oxford: Clarendon Press, 1995.

Sciaraffa, S., "On Content-Independent Reasons: It's not in the Name", en: Law and Philosophy 28, 2009, págs. 233-260. 
Responsabilidad, autoridad y democracia una exploración crítica ...

Searle, J., Expression and Meaning, Cambridge: Cambridge University Press, 1979.

Searle, J., Making the Social World, Oxford: Oxford University Press, 2010.

Silva Sánchez, J., "Prólogo", en: Kindhäuser, U. y Mañalich, J. P., 2011, págs. xiii-xxii.

Von Wright, G. H., Practical Reason, Oxford: Basil Blackwell, 1983.

Williams, B., Moral Luck, Cambridge: Cambridge University Press, 1982. 